\title{
Article
}

\section{The Mathematical Model of Curve-Face Gear and Time-Varying Meshing Characteristics of Compound Transmission}

\author{
Yanan $\mathrm{Hu}^{1}$, Chao Lin ${ }^{1} * \mathbb{D}^{\mathbb{D}}$, Shuo $\mathrm{Li}^{2}$, Yongquan $\mathrm{Yu}^{1}$, Chunjiang $\mathrm{He}^{3}$ and Zhiqin Cai ${ }^{4}$ \\ 1 The State Key Laboratory of Mechanical Transmission, Chongqing University, Chongqing 400044, China; \\ 20160702030@cqu.edu.cn (Y.H.); 20160702017@cqu.edu.cn (Y.Y.) \\ 2 The International Joint Laboratory for Light Alloys (Ministry of Education), College of Materials Science and \\ Engineering, Chongqing University, Chongqing 400045, China; 20150902021@cqu.edu.cn \\ 3 School of Mechanical and Power Engineering, Chongqing University of Science \& Technology, \\ Chongqing 401331, China; 20112407@cqu.edu.cn \\ 4 The School of Aeronautics and Astronautics, Xiamen University, Xiamen 361102, China; \\ caizhiqin@xmu.edu.cn \\ * Correspondence: linchao@cqu.edu.cn; Tel.: +86-13452911958
}

Citation: Hu, Y.; Lin, C.; Li, S.; Yu, Y.; He, C.; Cai, Z. The Mathematical Model of Curve-Face Gear and Time-Varying Meshing Characteristics of Compound Transmission. Appl. Sci. 2021, 11, 8706. https://doi.org/10.3390/ app11188706

Received: 31 July 2021

Accepted: 13 September 2021

Published: 18 September 2021

Publisher's Note: MDPI stays neutral with regard to jurisdictional claims in published maps and institutional affiliations.

Copyright: (c) 2021 by the authors. Licensee MDPI, Basel, Switzerland. This article is an open access article distributed under the terms and conditions of the Creative Commons Attribution (CC BY) license (https:// creativecommons.org/licenses/by/ $4.0 /)$.
Featured Application: According to the design requirements of the focusing mechanism of the space remote sensing camera, the curve-face gear compound transmission, a new type of gear pair with variable transmission ratio was used for the focusing mechanism. And Chongqing Graduate Student Research Innovation Project (CYB19011) applied by the first author is "Design and Research of the Precision Focusing Mechanism of Space Remote Sensing Camera".

Abstract: The curve-face gear pair is a new type of gear pair with variable transmission ratio for spatial finite helical motion. In this paper, mathematical models of a new developed curve-face gear were simplified and obtained directly by the standard shaper. The subsequent studies on the curveface gear compound transmission characteristics were further analyzed by the combinations of the principle of space gearing and screw theory. Firstly, the conjugate tooth surface geometry as well the point contact traces of curve-face gears were derived. Secondly, the geometric relationships between gear pair and the corresponding meshing characteristics were evaluated by several basic geometric elements, including instantaneous screw, axodes, striction curve, and conjugate pitch surface. Based on that analysis, it was found that the tooth contact normal was reciprocal to the instantaneous twist, which demonstrated that the conjugate motion with the desired transmission ratio could be realized in current curve-face gear compound transmission. Moreover, the time-varying slip characteristics of the curve-face gear pair were also revealed, that is, rolling and sliding action coexist at all contact on the tooth surfaces. In brief, this work provided the theoretical basis for following researches on machining curve-face gear with standard shaper.

Keywords: curve-face gear; mathematical model; spatial finite helical motion; point contact; reciprocity; relative displacement

\section{Introduction}

Space optical remote sensing camera is one of the important means to obtain terrestrial remote sensing images. It is widely used in the fields of meteorology, geological exploration, agriculture and forestry, ocean, environment, military, disaster relief, and so on [1]. The focusing mechanism is mainly to solve the effect of defocus on the image quality of space [2].

The traditional focusing mechanism is a combined transmission mechanism, which is mainly composed of two-stage worm gear pair reduction mechanism and eccentric cam or leadscrew nut mechanism [3]. Generally, with the increase of the complexity of motion law and trajectory requirements, the number of parts of the combined mechanism increases, the 
structure becomes complex, and the reliability of the mechanism often decreases. Therefore, the combined mechanism is not suitable for occasions where the structural size is limited and the motion law is too complex. According to the design requirements of the focusing mechanism of space remote sensing camera, the curve-face gear pair, a new type of gear pair with variable transmission ratio was used for the focusing mechanism. With the dual advantages of gear pair and cam pair [4], the curve-face gear compound transmission can adapt to heavy-duty and high-precision conditions such as aerospace [5]. Therefore, researches on the curve-face gear compound transmission is necessary, which can enrich the theory and expand the application of non-circular gears.

So far, the fundamental theory system of gear transmission has been established by using space vector and differential geometry as theoretical basis and mathematical tools [6-8]. Remarkably, screw theory was introduced into mechanism kinematics by many researchers, which can provide a deeper understanding of motion characteristics and promoted the engineering applications of space gears [9,10]. Hunt [11] used the theory of screw to study gear transmission. Dooner $[12,13]$ proposed the three laws of spatial gearing based on screw theory, and optimized the design concept of spatial and planar gear. Phillips [14] studied spatial involute gear transmission with skew axis by using the theory of screw as a mathematical tool. Therefore, screw theory and the principle of spatial gearing are expected to apply in characteristics analysis of curve-face gear compound transmission pair, which is of great significance to the design and practical applications of the curve-face gear pair.

As a new type of gear, the curved-face gear has been studied preliminarily. For common variable contact ratio transmission combined with non-cylindrical gear and curve-face gear, the mathematical equations for the tooth surface of non-circular gear and curve-face gear based on the external generating method with the same shaper cutter were established [15]; the equations of instantaneous contact ratio of helical curve-face gear pair are proposed by transforming helical curve-face gear pair into helical non-circular rack and pinion [16]; a calculating method of the tooth root bending strength of the eccentric straight and helical curve face gear was proposed [17]; the loaded tooth contact analysis of straight and helical curve-face gear pair were taken into consideration [18,19]; to study the nonlinear dynamic characteristics of curve-face gear drive, a generalized nonlinear dynamic model based on Lagrange Bond graphs was presented [20]. For compound transmission combined with cylindrical gear and curve-face gear, the movement characteristics of the compound curve-face gear transmission were analyzed, including transmission ratio, rotation, movement, and quick-return [21]; the calculation of meshing efficiency of compound motion has been proposed [22].

It can be seen that, compared with common variable contact ratio transmission, the research on curve-face gear compound transmission is not perfect. Specifically, the tooth surfaces in contact is the direct factor of the gear motion and power conversion, and the geometric characteristics of the tooth surface is one of the important factors to improve its performance [23]. Litvin [24] studied the fundamental principle of conjugation surface and gear geometry for complex gear surfaces. Yang [25] developed "Deviation-Function" method for generating new conjugate kinematic pairs using the principle of gearing and differential geometry theory. Liang [26] discussed the geometric and meshing properties of conjugate curves gear transmission. Zheng [27] proposed the concept of variable center distance gear transmission and establishes its mathematical model, which is applied to the shape generating of non-circular gears. And the spatial envelope applicable to generalized spatial gears is also proposed [28,29]. However, due to the complexity in geometry of tooth surface, tooth surface model of curve-face gear was usually obtained through simulating the process of generation by the non-circular shaper in previous researches [5]. To simplify the design and fabrication process, researches on the tooth surface model of curve-face gear acquired by the standard shaper is necessary.

On the other hand, once the tooth surface model was acquired by the standard gear shaper cutter, the contact characteristics of curve-face gear pair in mesh is supposed to 
investigate next. In the design of gearing with intersecting shaft, scholars have not only focused many special tooth surface types and established their mathematical models, but also analyzed their contact characteristics in mesh. Dooner [13] defined conjugate gear surfaces as two gears in direct contact that produce the desired speed ratio. And he believed, inherent in hypoid or skew axis gearing is relative motion between the two pitch surfaces along the common generator. Tseng [30] and Wu [31] carried out tooth contact analysis of arc cylindrical gear, and studied meshing transmission performance and contact characteristics. Bair [32] proposed the arc helical bevel gear, and made an example design and contact transmission analysis for this gear. Argyris [33] studied the computer aided geometric design and the computerized simulation of meshing and contact of arc bevel gear pair. Fan [34] proposed a computer modeling and contact analysis method for arc bevel gears and hypoid gears. Chen [35] presented a complete mathematical model of a helical gear set with small number of teeth. Hence, the curve-face gear compound transmission pair is regard as a space three link 1-dof mechanism, space vector and gear geometry would be the important means for the geometry analysis of tooth surface, as well the principle of spatial gearing and screw theory can be the main tools for the characteristics analysis of conjugate action in mesh.

At the same time, in order to meet the requirements of high quality and low noise gear mass production, the quality control and accuracy detection of gear surface is particularly important. Golebski proposed a method to allow the production of cylindrical gears with a tooth and profile line other than the standard [36], and the comparsion of measuring methods for the involute profile of the spur gear tooth was described [37]. And the method of machining gears by the step-by-step method has been also proposed, which can be used in unit machining of large-module gears with an arbitrary profile modification system [38]. Heath and Filler [39] proposed a method for measuring tooth pitch deviation of face gear by using a gear measuring center. Wang [40] proposed that the normal deviation of face gear tooth surface was used as the standard for evaluating the machining accuracy of face gear tooth surface.

In this paper, the geometry of the curve-face gear surface will be generated by simulated meshing of the shaper and curve-face gear, and its mathematical model was established. Instead of the simulation processing by non-circular shaper in previous researches with SolidWorks [41], this method fills the blank of mathematical modeling of curve-face gear tooth surface. Based on meshing of general curve-face gear pair in line contact [42], the contact and slip characteristics of tooth surface, and the motion characteristics of compound transmission are also analyzed. This work provides a theoretical basis for the subsequent processing of curve-face surface gear by standard shaper and the design of the spatial finite helical motion of the curve-face gear compound transmission with variable transmission ratio.

\section{Geometric Modeling of Conjugate Curve-Face Gear Tooth Surface}

Instead of the traditional combined transmission for focusing mechanism, which is mainly composed of two-stage worm gear pair reduction mechanism and eccentric cam or leadscrew nut mechanism, a new type of gear pair with variable transmission ratio, the curve-face gear compound transmission, was used for the focusing mechanism of space remote sensing camera as shown in Figure 1.

While the input rotates about a fixed axis, the displacement of the focusing plane as the outputting element of this new focusing mechanism will be translational.

Inspired by the manufacture of face gear by a shaper by Fellows Corporation [16], the method of simulating the meshing between the generating shaper and the generated curve-face gear, as the meshing between the driving pinion and curve-face gear, is used to process the curve-face gear. 


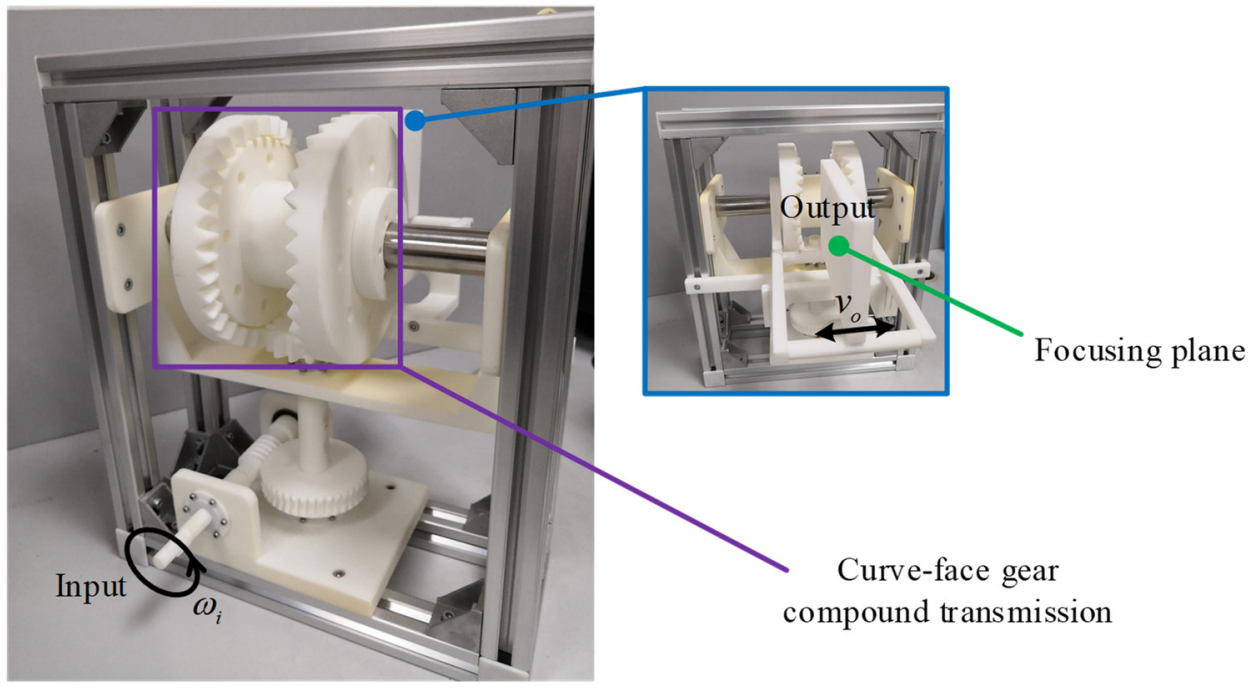

Figure 1. The focusing mechanism of space remote sensing camera with curve-face gear compound transmission.

The tooth surface of curve-face gear $\Sigma_{2}$ is determined as the envelope to the family of surfaces generated in coordinate system $S_{2}$ by shaper surface $\Sigma_{s}$ represented in $S_{s}$. To derive the equations of curve-face gear surfaces, the following coordinate systems in Figure 2 are used.

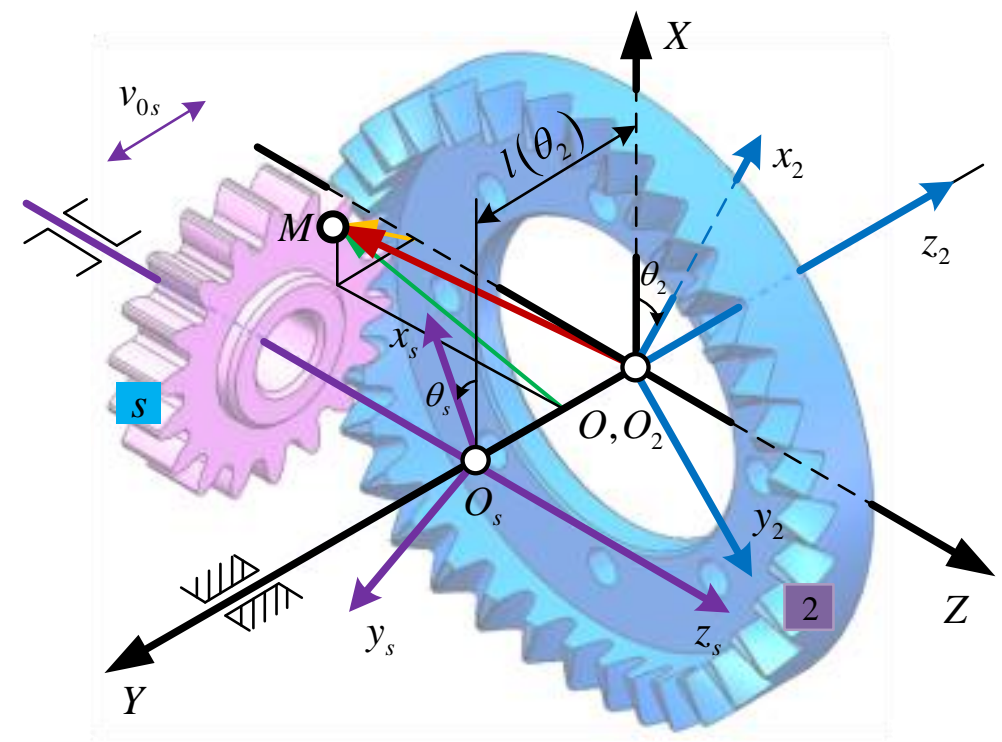

Figure 2. The coordinate systems for manufacture curve-face gears.

As shown in Figure 2, consider coordinate system $S(O-X Y Z), S_{s}\left(O_{s}-x_{s} y_{s} z_{s}\right)$ and $S_{2}\left(O_{2}-x_{2} y_{z} z_{2}\right)$ that are rigidly connected to the engine base of machine tool $f$, shaper $s$ and curve-face gear 2, respectively. Here, the rotation axis of shaper is parallel to the Z-axis of the frame coordinate system $S$, and translates along the $Y$-axis. The rotation axis of the curve-face gear coincides with the $Y$-axis of the frame coordinate system $S$. Consequently, in process of generation, the shaper moves in a planar complex curve, and the curve-face gear rotates about a fixed axis.

\subsection{The Equations of Shaper Surface}

We consider that the tooth profile is represented in plane perpendicular to $Z_{s}$-axis, and in order to maximize the involute tooth profile, as shown in Figure 3, the base circle of 
shaper divides the tooth profile of shaper into two regions: involute tooth profile ${ }_{M_{A}} M_{B}$ and fillet tooth profile $\hat{M_{B} M_{F}}$.

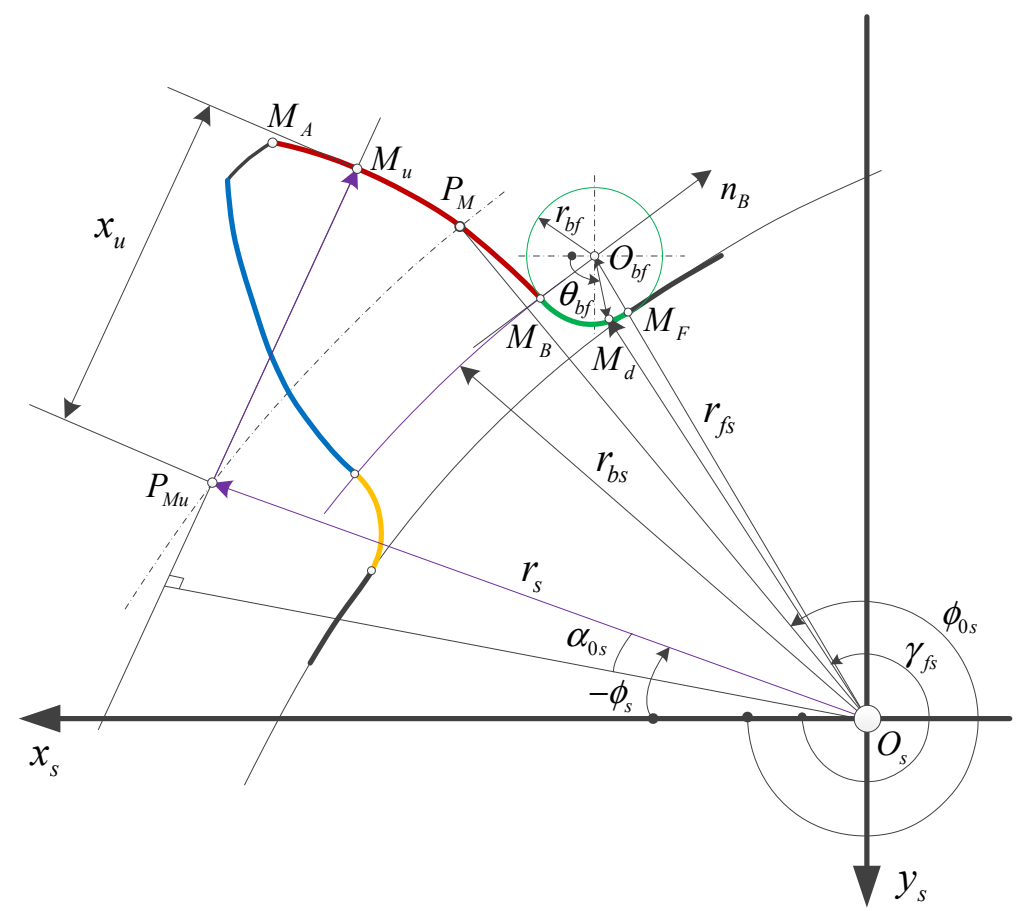

Figure 3. The tooth profile of shaper.

As shown in Figure 3 , in coordinate system $S_{s}\left(O_{s}-x_{s} y_{s} z_{s}\right), P_{M}, M_{A}$, and $M_{B}$ are the intersection points of the pitch circle, the addendum circle, and the base circle with the right involute tooth profile of the gear shaper cutter, respectively, and $M_{F}$ is the intersection point of the dedendum circle with the right fillet tooth profile of the gear shaper cutter.

\subsubsection{The Involute Tooth Profile}

On the plane $x_{s} O_{s} y_{s}$, the position vector of one point $M_{u}$ on the right involute tooth profile of the shaper can be expressed as a vector loop equation:

$$
\mathrm{O}_{s} \vec{M}_{u}=O_{s} \vec{P}_{M u}+P_{M u} M_{u}
$$

Here, $u_{s}$ is used to represent the parameter of the tooth surface $\Sigma_{s}$ in $z_{S}$ direction. Further, $\left(\phi_{s}, u_{s}\right)$ are the Gaussian coordinates of the shaper tooth surface $\Sigma_{s}$. In addition, the vector of pitch point $O_{s} \vec{P}_{M u}=r_{s}\left(\sin \phi_{s},-\cos \phi_{s}\right)^{T}$, and the generating vector $\overrightarrow{P_{M u}} \overrightarrow{M_{u}}=x_{u}\left[-\cos \left(\phi_{s}+\alpha_{0 s}\right),-\sin \left(\phi_{s}+\alpha_{0 s}\right)\right]^{T}$, among which the length $x_{u}$ of generating line is $r_{s}\left(\phi_{s}-\phi_{0 s}\right) \cos \alpha_{0 s}$.

In coordinate system $S_{s}$, the homogeneous coordinates of involute tooth profile of the shaper becomes:

$$
\vec{r}_{s M}\left(\phi_{s}, u_{s}\right)=\left[\begin{array}{c}
r_{s}\left[\cos \phi_{s}+\left(\phi_{s}-\phi_{0 s}\right) \cos \alpha_{0 s} \sin \left(\phi_{s} \pm \alpha_{0 s}\right)\right] \\
r_{s}\left[\sin \phi_{s}-\left(\phi_{s}-\phi_{0 s}\right) \cos \alpha_{0 s} \cos \left(\phi_{s} \pm \alpha_{0 s}\right)\right] \\
u_{s} \\
1
\end{array}\right]
$$

where, the upper symbol is used for the right tooth profile of the shaper, and then, $\phi_{s} \in$ $\left[\phi_{0 s}-e_{b}, \phi_{0 s}+e_{a}\right], \phi_{0 s}=(2 n-2) \pi / z_{s}$; the lower symbol is used for the left tooth profile of the shaper, here, $\phi_{s} \in\left[\phi_{0 s}-e_{a}, \phi_{0 s}+e_{b}\right]$, and $\phi_{0 s}=(2 n-1) \pi / z_{s}$. By the way, $e_{b}=$ $\theta_{0 s}+\alpha_{0 s}$, and $e_{a}=\left(\theta_{a s}-\theta_{0 s}\right)+\left(\alpha_{a s}-\alpha_{0 s}\right)$, in which $\alpha_{0 s}$ and $\alpha_{a s}$ are pressure angles at 
point $P_{M}$ and point $M_{A}$, respectively; $\theta_{0 s}$ and $\theta_{a s}$ are generating angles of involute tooth profile at point $P_{M}$ and point $M_{A}$, respectively.

\subsubsection{The Fillet Tooth Profile}

Assuming that the radius of the fillet tooth profile is $r_{b f}$, the fillet tooth profile is tangent to the dedendum circle of the shaper at point $M_{F}$. According to the vector relation and the tangent property of the two circles, which

$$
\left\{\begin{array}{l}
\vec{O}_{s} O_{b f}=\vec{O}_{s} \vec{M}_{F}+M_{F} \vec{O}_{b f} \\
\left|\vec{O}_{s} \vec{O}_{b f}\right|=r_{b f}+r_{f s}
\end{array}\right.
$$

The radius of the fillet tooth profile $r_{b f}$

$$
r_{b f}=\frac{r_{b s}^{2}-r_{f s}^{2}}{2 r_{f s}}
$$
shaper

In coordinate system $S_{s}$, the homogeneous coordinates of the fillet tooth profile of the

$$
\vec{r}_{s M}\left(\theta_{b f}, u_{s}\right)=\left[\begin{array}{c}
r_{b f} \cos \theta_{b f}+\left(r_{b s} \cos \Phi_{0 s} \pm r_{b f} \sin \Phi_{0 s}\right) \\
r_{b f} \sin \theta_{b f} \mp\left(r_{b s} \sin \Phi_{0 s} \pm r_{b f} \cos \Phi_{0 s}\right) \\
u_{s} \\
1
\end{array}\right]
$$

Similarly, the upper and lower symbols are used for the right and left tooth profiles of the shaper, respectively.

By visualizing the tooth profile of shaper with MATLAB, the model shown in Figure 4 can be obtained, and its unit is $\mathrm{mm}$.
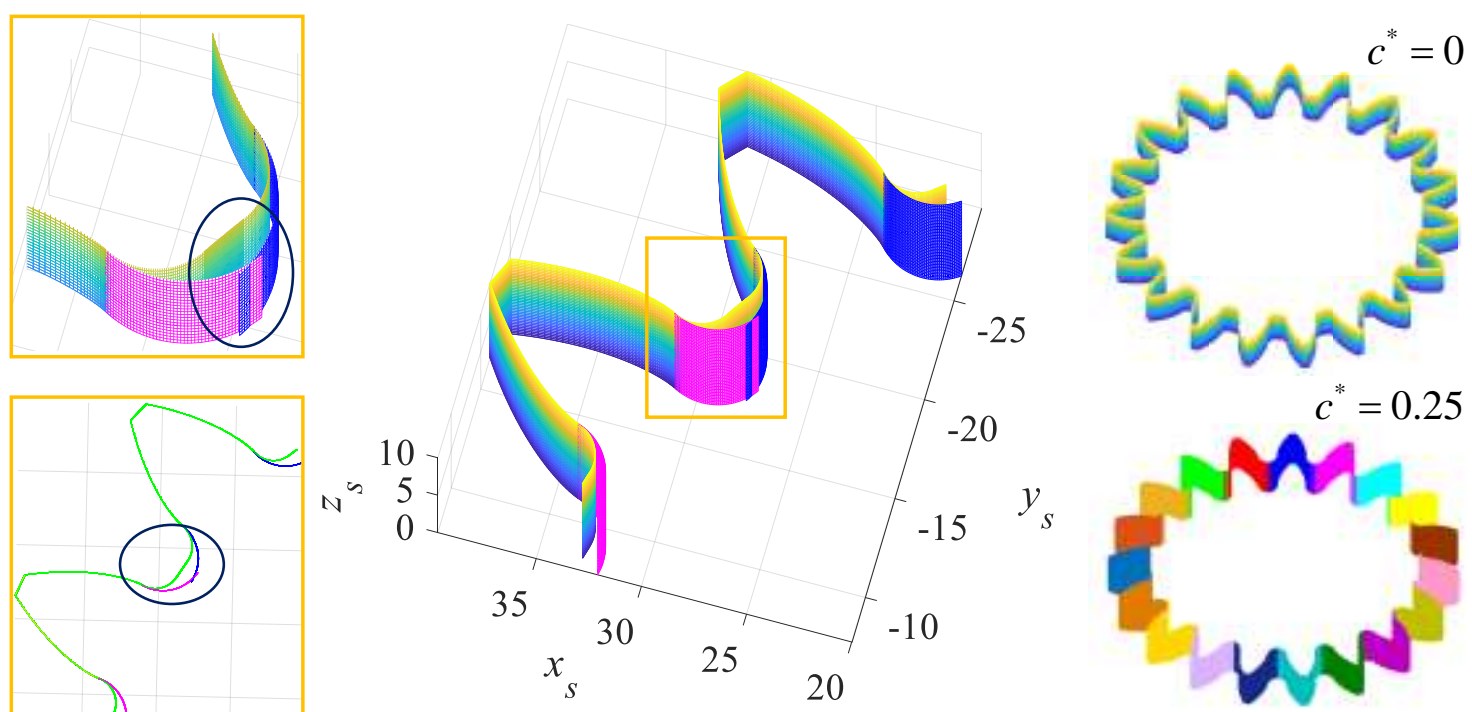

Figure 4. Tooth profile model of the shaper.

As depicted in Figure 4, different clearances directly affect the magnitude of fillet radius of the shaper. The clearance constant $c^{*}$ of the shaper model used in this paper is 0.25 . Because, although there is a cross phenomenon on the dedendum circle of shaper, the top clearance design can be still considered while retaining the involute tooth profile to the maximum. 


\subsection{Equations of Curve-Face Gear Surface}

The family of the shaper tooth surface $\Sigma_{s}$ in coordinate system $S_{2}$ can be expressed

$$
\vec{r}_{2}^{(2)}\left(\theta_{s}, \phi_{s}, u_{s}\right)=M_{2 s}\left(\theta_{s}\right) \vec{r}_{s}^{(s)}\left(\phi_{s}, u_{s}\right)
$$

Moreover, the coordinate transformation in transition from $S_{s}$ to $S_{2}$ is represented by the matrix:

$$
M_{2 s}\left(\theta_{s}\right)=M_{2 f} M_{f_{s}}=\left[\begin{array}{cccc}
\cos \theta_{2} \cos \theta_{s} & -\cos \theta_{2} \sin \theta_{s} & \sin \theta_{2} & 0 \\
-\sin \theta_{2} \cos \theta_{s} & \sin \theta_{2} \sin \theta_{s} & \cos \theta_{2} & 0 \\
-\sin \theta_{s} & -\cos \theta_{s} & 0 & -l\left(\theta_{2}\right) \\
0 & 0 & 0 & 1
\end{array}\right]
$$

where, $\theta_{s}$ and $\theta_{2}$ are the angular displacements of shaper and curve-face gear, respectively, $l\left(\theta_{2}\right)$ is the axial displacements of shaper. Known in advance that the rotation angle of shaper can be calculated as $\theta_{S}\left(\theta_{2}\right)=\int_{0}^{\theta_{2}} \sqrt{R^{2}+f \prime^{2}(\theta)} d \theta / r_{s}$, in terms of the fundamental transmission geometry relation through subsequent calculation in Section 3.1.

To simplify the derivations of the equation of meshing, the frame coordinate system $S$ is preferable to be used for the relative velocity vector $\vec{v}_{s 2}^{(f)}$ and unit normal vector $\vec{n}_{s}^{(f)}$ to shaper tooth surface at any candidate point $M$ in mesh. The relative velocity between two gear teeth in direct contact can be found in $S$

$$
\vec{v}_{s 2}^{(f)}=\left[\begin{array}{c}
-\left(x_{s} \sin \theta_{s}+y_{s} \cos \theta_{s}\right) \omega_{s}+z_{s} \omega_{2} \\
\left(x_{s} \cos \theta_{s}-y_{s} \sin \theta_{s}\right) \omega_{s}+v_{0 s} \\
-\left(x_{s} \cos \theta_{s}-y_{s} \sin \theta_{s}\right) \omega_{2}
\end{array}\right]
$$

The equation of meshing between shaper $\Sigma_{s}$ and curve-face gear $\Sigma_{2}$

$$
\begin{aligned}
f\left(\theta_{s}, \phi_{s}, u_{s}\right) & =\vec{n}_{s}^{(f)} \cdot \vec{v}_{s 2}^{(f)} \\
& =-r_{s} \cos \alpha_{0 s} \omega_{s}+u_{s} \omega_{2} \sin \left(\theta_{s}+\phi_{s} \pm \alpha_{0 s}\right)-v_{0 s} \cos \left(\theta_{s}+\phi_{s} \pm \alpha_{0 s}\right) \\
& =0
\end{aligned}
$$

The curve-face gear tooth surface $\Sigma_{2}$ can be obtained by the envelope to the family of surfaces $\Sigma_{s}$. Consequently, the equations of the generated curve-face gear surface can be expressed by vector function $\vec{r}_{2}^{(2)}\left(\theta_{s}, \phi_{s}\right)$ and the equation of meshing $f\left(\theta_{s}, \phi_{s}, u_{s}\right)=0$, that is:

$$
\vec{r}^{(2)}\left(\theta_{s}, \phi_{s}\right)=\left[\begin{array}{c}
r_{s} \cos \theta_{2}\left[\cos \left(\theta_{s}+\phi_{s}\right)+\left(\phi_{s}-\phi_{0 s}\right) \cos \alpha_{0 s} \sin \left(\theta_{s}+\phi_{s} \pm \alpha_{0 s}\right)\right]+\sin \theta_{2} u_{s}\left(\theta_{s}, \phi_{s}\right) \\
-r_{s} \sin \theta_{2}\left[\cos \left(\theta_{s}+\phi_{s}\right)+\left(\phi_{s}-\phi_{0 s}\right) \cos \alpha_{0 s} \sin \left(\theta_{s}+\phi_{s} \pm \alpha_{0 s}\right)\right]+\cos \theta_{2} u_{s}\left(\theta_{s}, \phi_{s}\right) \\
r_{s}\left[-\sin \left(\theta_{s}+\phi_{s}\right)+\left(\phi_{s}-\phi_{0 s}\right) \cos \alpha_{0 s} \cos \left(\theta_{s}+\phi_{s} \pm \alpha_{0 s}\right)\right]-l\left(\theta_{2}\right)
\end{array}\right]
$$

where $u_{s}\left(\theta_{s}, \phi_{s}\right)=\frac{r_{b s}+i_{2 s}\left(\theta_{2}\right) l^{\prime}\left(\theta_{2}\right) \cos \left(\theta_{s}+\phi_{s} \pm \alpha_{0 s}\right)}{i_{2 s}\left(\theta_{2}\right) \sin \left(\theta_{s}+\phi_{s} \pm \alpha_{0 s}\right)}$. Likewise, the upper and lower symbol are used for the right and left tooth profile of the generated curve-face gear, respectively.

Figure 5 shows the models of the left involute tooth surface equation visualized by MATLAB, and the unit of the models are $\mathrm{mm}$. 


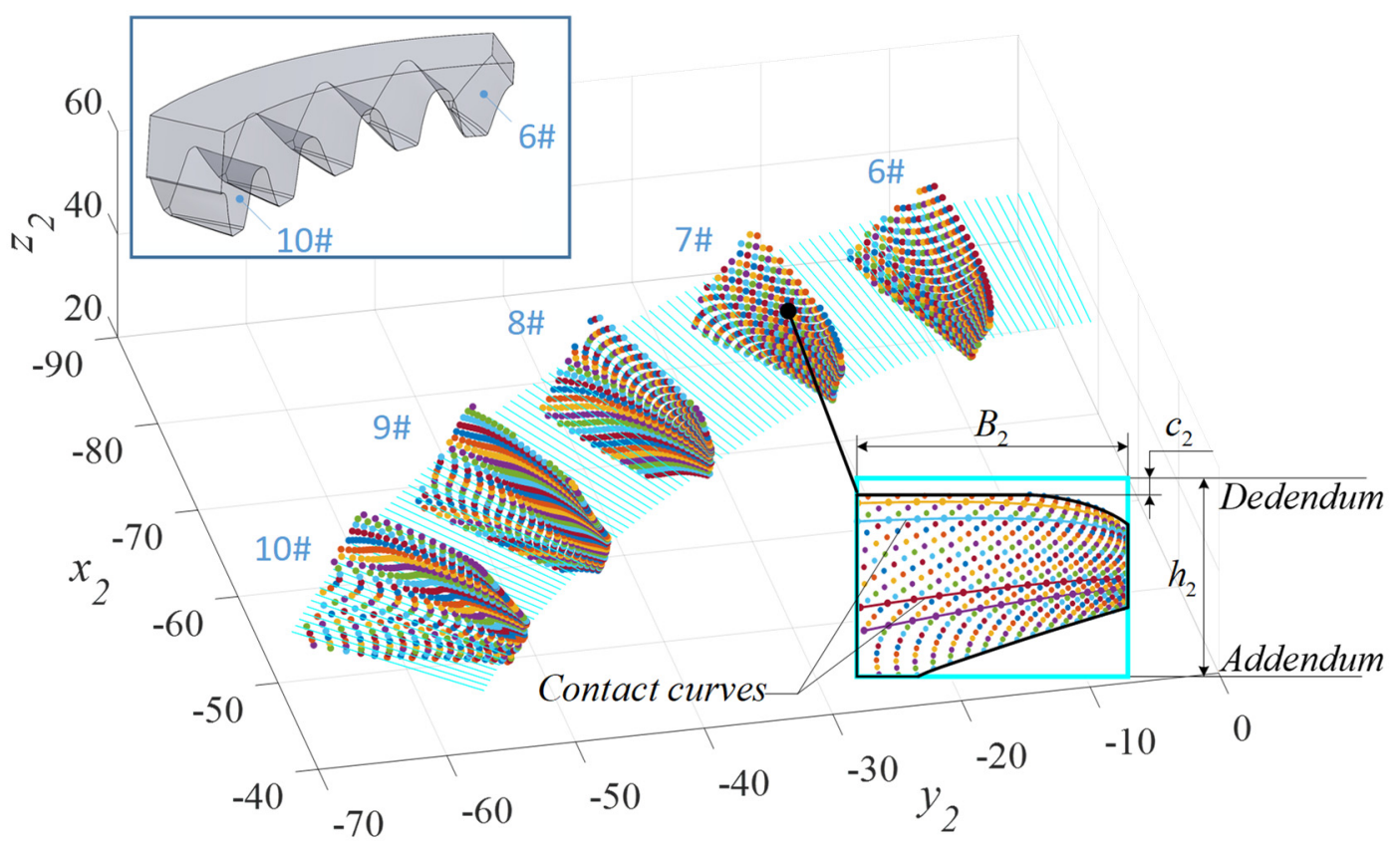

Figure 5. The left involute tooth profile of the curve-face gear in a cycle.

As depicted in the partial enlarged version of Figure 5, the contact curves on the curve-face gear tooth surface $\Sigma_{2}$ correspond to the meshing of the shaper with curve-face gear. In addition, $B_{2}, c_{2}$ and $h_{2}$ are correspondingly tooth width, clearance and whole depth of the curve-face gear, respectively.

It is worth noting that, the surfaces of the curve-face gear and cylindrical gear with the same specification as the shaper are also in line contact in the process of meshing. Besides, according to the conditions of undercutting and pointing, the determination of tooth width of curve-face gears has been discussed in detail in our previous research [42], so those won't be covered again here.

\section{The Spatial Finite Helical Motion for Compound Transmission}

Generally, there are three motion transmission types of the gear pair combination of cylindrical gear and curve-face gear. The specific models and fundamental properties of three cases are summarized in Table 1. For example, in Case II, the cylindrical gear as the input element rotates about the fixed input axis. The curve-face gear outputs the finite helical motion in space, which rotates about and moves along the fixed output axis. The specific models and fundamental properties of these three cases are shown in Table 1.

In Table 1, 1\# gear is the driving gear, and 2\# gear is the driven gear. The Case I is mainly applied to the generation of curve-face gears by shaper as described in Section 2.2. In the process of generation, the two tooth surfaces are in line contact at every instant. The Cases II and III are mostly used to transmit mechanical motion and power. However, the two tooth surfaces in Case II and III are usually in point contact, which is less sensitive to misalignment. In this regard, Case II is a deceleration mechanism with an output of spatial finite helical motion, while the Case III is an acceleration mechanism with the output of planar complex curved motion.

Consider again coordinate system $S(O-X Y Z), S_{1}\left(O_{1}-x_{1} y_{1} z_{1}\right)$ and $S_{2}\left(O_{2}-x_{2} y_{z} z_{2}\right)$ are rigidly connected to the engine base of machine tool $f$, cylindrical gear 1 and curve-face gear 2, respectively. Without any loss of generality, the screw axis $\Phi_{1}$ of the input reference frame $S_{1}$ is selected such that it coincides with the $Z$-axis of the fixed reference frame $S$. The screw axis $\underline{\Phi}_{2}$ of the output reference frame $S_{2}$ is aligned with the $Y$-axis of the fixed reference frame $S$. The included angle $\theta_{1}$ between the $X$-axis and $x_{1}$-axis, determined as the angular displacement of cylindrical gear, is a counterclockwise rotation about the fixed $Z$-axis. The clockwise rotation angle $\theta_{2}$ and displacement $l\left(\theta_{1}\right)$ of the curve-face gear 
coordinate system relative to the fixed coordinate system $S$ along the $Y$-axis are the angular displacement and axial displacement of the curve-face gear, respectively.

Table 1. Three motion transmission types of cylindrical gear and curve-face gear pair.

\begin{tabular}{cccc}
\hline Types & Case I & Case III \\
\hline Kinds & Reduction mechanism & Reduction mechanism & Acceleration mechanism \\
\hline Input & Moving-axis rotation & Fixed-axis rotation & Moving-axis \\
\hline Output & Fixed-axis & Spatial finite helical motion & Planar complex curvilinear motion \\
\hline
\end{tabular}

In fact, gear pairs are usually used for speed reduction, and mechanical power is commonly and easily transmitted by a fixed axis with uniform rotation, therefore, the following work will focus on Case II, which is generally the case in gearing. Actually, different from the common curve-face gear transmission formed by non-circular gear and curve-face gear with variable transmission ratio [41], the gear pair combination of cylindrical gear and curve-face gear in Case II is defined as curve-face gear compound transmission.

Following, screw theory is used as the basis for the geometric foundation to parameterize the kinematic geometry of motion transmission between intersecting axes.

\subsection{Basic Kinematic Relation}

In order to facilitate the study of the curve-face gear compound transmission, the right-handed Cartesian coordinate systems as shown in Figure 6 are established.

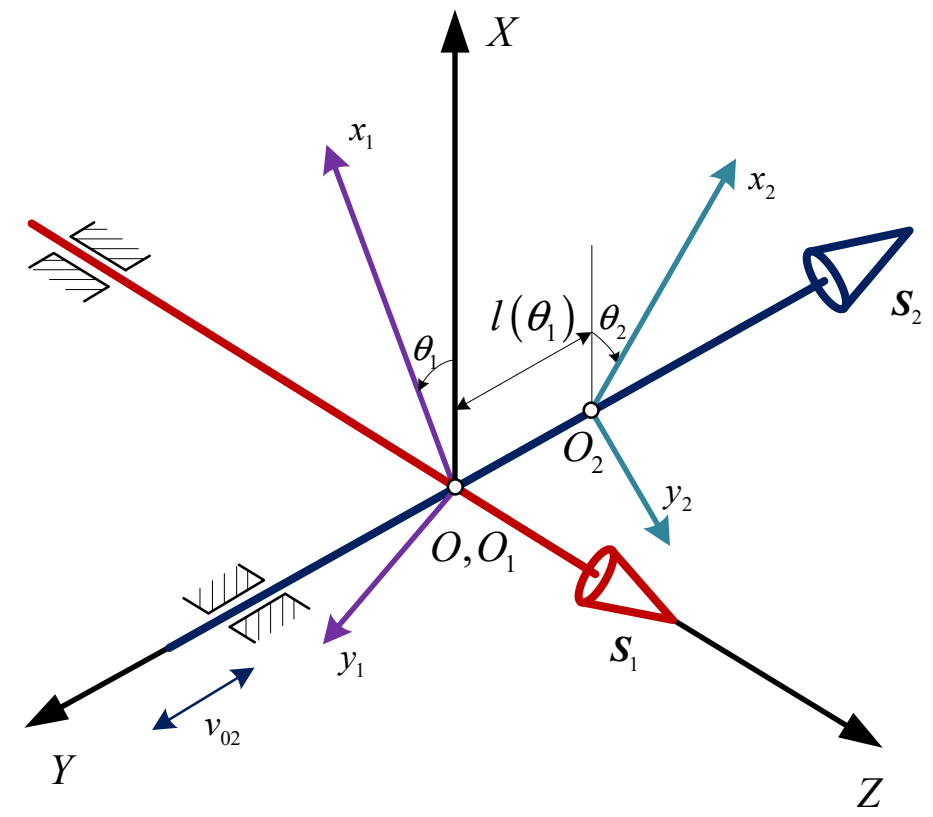

Figure 6. The motion coordinate systems of curve-face gear compound transmission. 
The transmission ratio of curve-face gear compound transmission in this paper is a scalar and defined as $i\left(\theta_{1}\right)=\omega_{2} / \omega_{1}$.

And then, the angular displacement $\theta_{2}$ of the curve-face gear is:

$$
\theta_{2}\left(\theta_{1}\right)=\int_{0}^{\theta_{1}} i(\theta) d \theta
$$

The axial displacement $l\left(\theta_{1}\right)$ of the curve-face gear is:

$$
l\left(\theta_{1}\right)=\int_{0}^{\theta_{1}} \sqrt{r^{2}-(R \cdot i)^{2}} d \theta+R \cdot i\left(\theta_{1}\right)-r
$$

Further, axial velocity $v_{0}\left(\theta_{1}\right)$ of the curve-face gear can be calculated as:

$$
v_{0}\left(\theta_{1}\right)=\frac{d l\left(\theta_{1}\right)}{d t}=\omega_{1} \sqrt{r^{2}-\left[R \cdot i\left(\theta_{1}\right)\right]^{2}}+\omega_{1} R \cdot i^{\prime}\left(\theta_{1}\right)
$$

The basic kinematic relation of the curve-face gear compound transmission is shown in Figure 7 , including the output angular displacement $\theta_{2}$, the transmission ratio $i\left(\theta_{1}\right)$, and the axial displacement $l\left(\theta_{1}\right)$ and velocity $v_{0}\left(\theta_{1}\right)$ of the curve-face gear, which takes the input angular displacement $\theta_{1}$ as the independent variable.

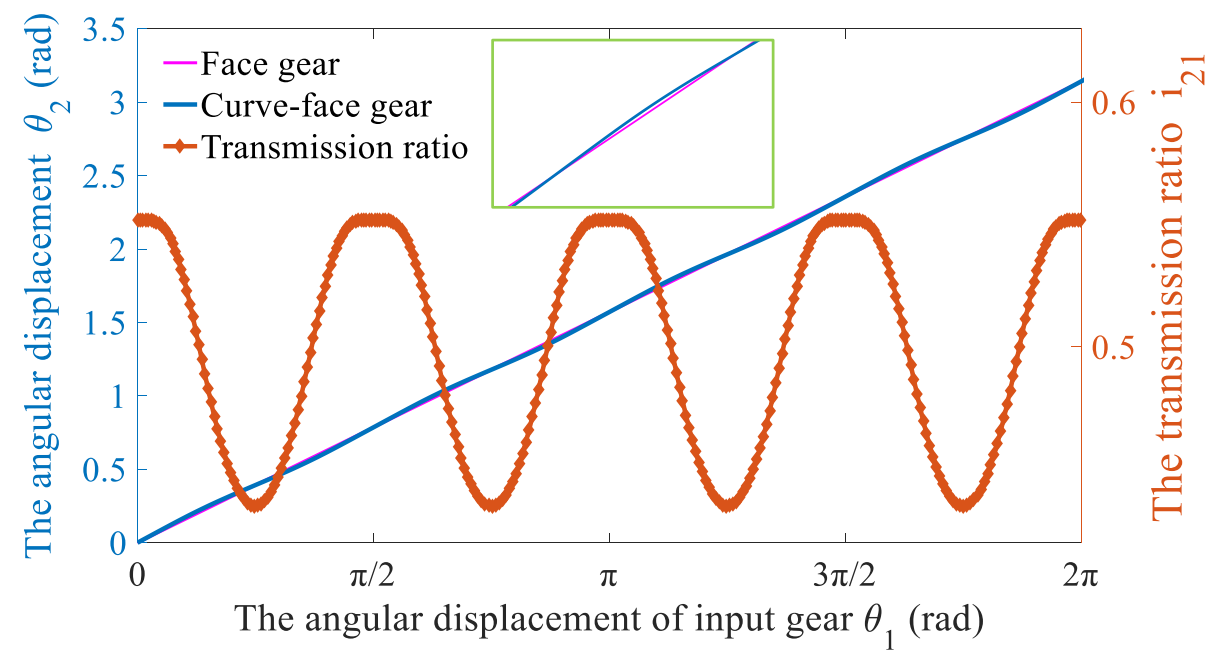

(a) the output angular displacement and transmission ratio

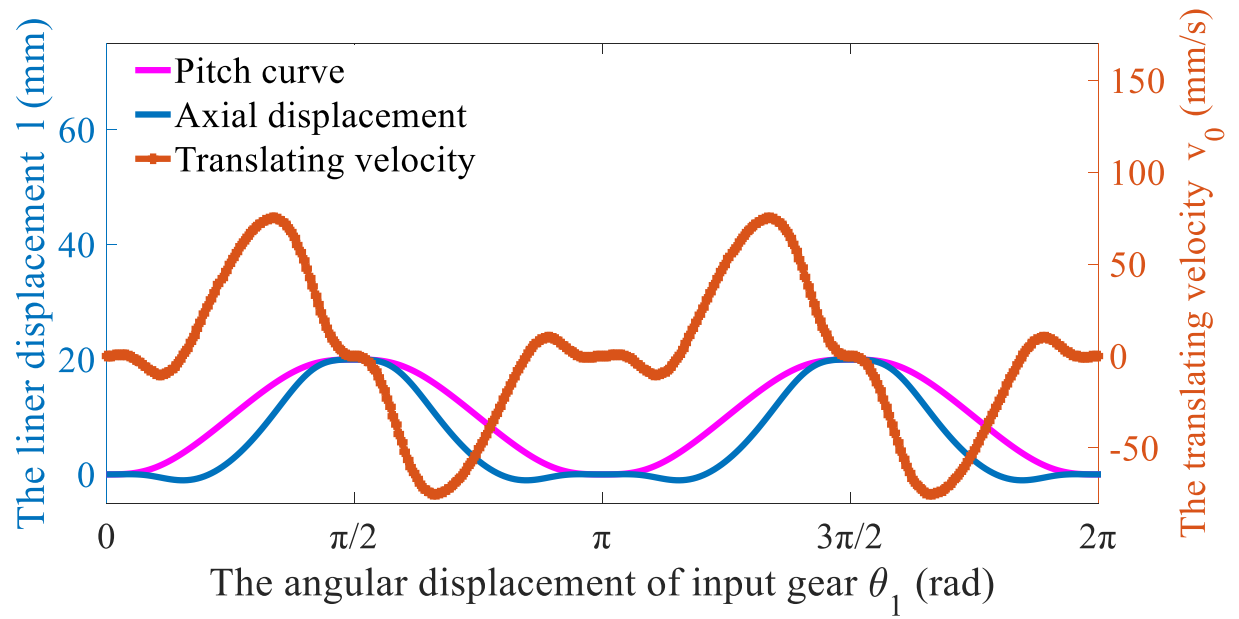

(b) the axial displacement and velocity of the curve-face gear

Figure 7. The basic kinematic relation of the curve-face gear compound transmission. 


\subsection{Conjugate Pitch Surfaces}

Dooner [12] pointed out that pitch surfaces can be specified once the coordinates for $\Phi_{i}$ and $\Phi_{0}$ are known; however, the axodes cannot be determined until the I/O relationship is specified, which is further discussed in Section 3.3. When the curve-face gear compound transmission is installed in standard without considering the installation error, the pitch surface of the cylindrical gear is a cylindrical surface. In the coordinate system $S_{1}$ rigidly connected with the cylindrical gear, the pitch surface equation of the cylindrical gear is:

$$
\vec{r}_{a 1}^{(1)}\left(\phi_{1}, u_{1}\right)=\left[\begin{array}{c}
x_{d 1} \\
y_{d 1} \\
z_{d 1}
\end{array}\right]=\left[\begin{array}{c}
r_{1} \cos \phi_{1} \\
r_{1} \sin \phi_{1} \\
u_{1}
\end{array}\right]
$$

According to the principle of gearing and coordinate transformation, the reference pitch surface equation of the curve-face gear is:

$$
\vec{r}_{d 2}^{(2)}\left(\theta_{2}, \phi_{s}, u_{s}\right)=M_{2 s}\left(\theta_{2}\right) \vec{r}_{d s}^{(s)}\left(\phi_{s}, u_{s}\right)=\left[\begin{array}{c}
r_{s} \cos \theta_{2} \cos \left(\theta_{s}+\phi_{s}\right)+u_{s} \sin \theta_{2} \\
-r_{s} \sin \theta_{2} \cos \left(\theta_{s}+\phi_{s}\right)+u_{s} \cos \theta_{2} \\
-r_{s} \sin \left(\theta_{s}+\phi_{s}\right)-l\left(\theta_{2}\right) \\
1
\end{array}\right]
$$

The conjugate pitch surfaces of curve-face gear compound transmission are shown in Figure 8 , and the unit of the pitch surfaces are $\mathrm{mm}$. As well, the pitch surface of curve-face gear is a ruled surface.

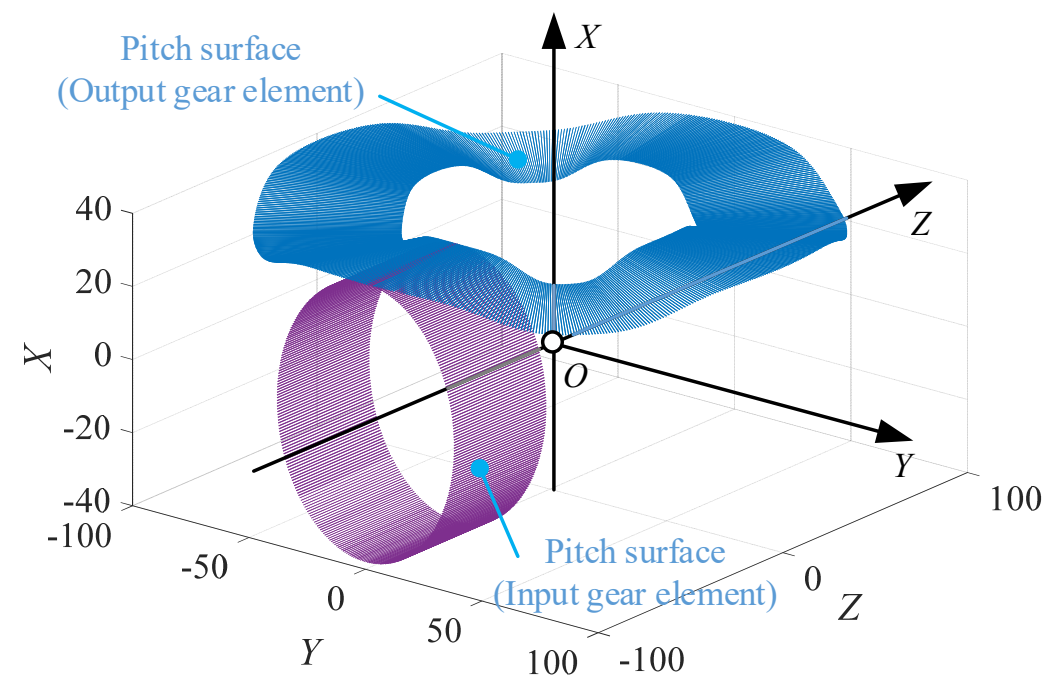

Figure 8. The conjugate pitch surfaces of curve-face gear compound transmission.

\subsection{Compound Transmission Axodes}

It must be admitted that all finite and infinitesimal motions of a rigid body can be equivalent to a finite helical motion combination of rotation about an axis and translation along that axis. In terms of the spatial mechanism theory [11], the curve-face gear compound transmission pair can be regard as a space three link 1-dof mechanism. Furthermore, an axode-based theory analogous to that used to design and manufacture the curve-face gear compound transmission by using screw theory.

\subsubsection{Instantaneous Screw Axis}

The instantaneous screw axis (ISA) can be determined according two mutually perpendicular and intersecting input and output shafts arranged in space illustrated in Figure 6, which is the common generator for the axodes. Note that, unlike ISA, the instantaneous 
screw (IS) is an instantaneous generator vector with pitch component according to the magnitude of the I/O relationship.

In reference to Ref. [9], the main vector of the twist is the rotational direction of the rigid body, and the dual vector essentially represents the instantaneous linear velocity of the point that coincides with the origin $O$ on the rigid body. Unless otherwise stated hereinafter, the coordinate system using for screw and vector is fixed coordinate system $S$.

According to the definition above, the input twist $S_{1}$ of cylindrical gear is:

$$
S_{1}=\left(\begin{array}{l}
\vec{C}_{1} \\
\vec{\xi}_{1}
\end{array}\right)=\left(0,0, \omega_{1} ; 0,0,0\right)^{T}
$$

where, $\vec{C}_{1}$ and $\vec{\xi}_{1}$ are correspondingly the primary part and secondary part of the input twist $S_{1}$.

And the output twist $S_{2}$ of curve-face gear is:

$$
S_{2}\left(\theta_{1}\right)=\left(\begin{array}{c}
\vec{C}_{2} \\
\vec{\xi}_{2}
\end{array}\right)=\left(0,-\omega_{2}\left(\theta_{1}\right), 0 ; 0,-v_{0}\left(\theta_{1}\right), 0\right)^{T}
$$

Similarly, $\vec{C}_{2}$ and $\vec{\xi}_{2}$ are the primary and secondary part of the output twist $S_{2}$, respectively.

According to the theorem of three axes, the homogeneous screw coordinate of the instantaneous screw $S_{i s}$ of the curve-face gear with respect to the cylindrical gear is:

$$
S_{i s}\left(\theta_{1}\right)=S_{2}\left(\theta_{1}\right)-S_{1}=\left(\begin{array}{c}
\vec{C}_{i s} \\
\overrightarrow{\xi_{i s}}
\end{array}\right)=\left(0,-\omega_{2}\left(\theta_{1}\right),-\omega_{1} ; 0,-v_{0}\left(\theta_{1}\right), 0\right)^{T}
$$

Then, the direction vector $\vec{s}_{i s a}$ of the instantaneous screw axis is $-\left(0, i\left(\theta_{1}\right), 1\right) / \sqrt{1+i^{2}\left(\theta_{1}\right)}$; and the relative angular velocity $\omega_{i s}$ between the input and output gear elements is:

$$
\omega_{i s}\left(\theta_{1}\right)=\omega_{1} \sqrt{1+i^{2}\left(\theta_{1}\right)}
$$

And the pitch $h_{i s}$ of the instantaneous screw $S_{i s}$ is:

$$
h_{i s}\left(\theta_{1}\right)=\frac{\overrightarrow{C_{i s}} \cdot \overrightarrow{\xi_{i s}}}{\overrightarrow{C_{i s}} \cdot \overrightarrow{C_{i s}}}=\frac{i\left(\theta_{1}\right) v_{0}\left(\theta_{1}\right)}{\sqrt{1+i^{2}\left(\theta_{1}\right)}}
$$

The translation component $h_{i s} \vec{\omega}_{i s}$ of the instantaneous screw $S_{i s}$ is equal to the axial component of the relative velocity between two gears in the direction of the screw axis. According to the Equation (20), the pitch $h_{i s}$ of the instantaneous screw can never be zero during the whole motion for compound transmission. That is, there is relative motion between two conjugate tooth surfaces along the instantaneous axis direction. Furthermore, the relative motion between the two gears is a spatial finite helical motion along the instantaneous axis. It is obvious that there is no pure rolling contact point whose relative velocity $\vec{v}_{21}$ is zero in the whole space.

In the fixed coordinate system $S$, the instantaneous screw axis equation $I_{i s a}$ of the curve-face gear compound transmission pair can be expressed as:

$$
I_{i s a}\left(\theta_{1}, m\right)=\left\{\begin{array}{l}
x_{i s a}=-l^{\prime}\left(\theta_{1}\right) /\left[1+i^{2}\left(\theta_{1}\right)\right] \\
y_{i s a}=-i\left(\theta_{1}\right) m \\
z_{i s a}=-m
\end{array}\right.
$$


Here, $t$ is the distance from any point on the instantaneous screw axis to the position vector $\vec{r}_{i s a}$. At a certain moment, the spatial position of the instantaneous screw axis of the curve-face gear compound transmission pair is shown in Figure 9. It is obvious that the instantaneous screw axis located on the plane $\alpha$ passes through the $X$-axis. The plane $\alpha$ is parallel to the YOZ-plane and the distance from each plane is $l^{\prime}\left(\theta_{1}\right) /\left[1+i^{2}\left(\theta_{1}\right)\right]$.

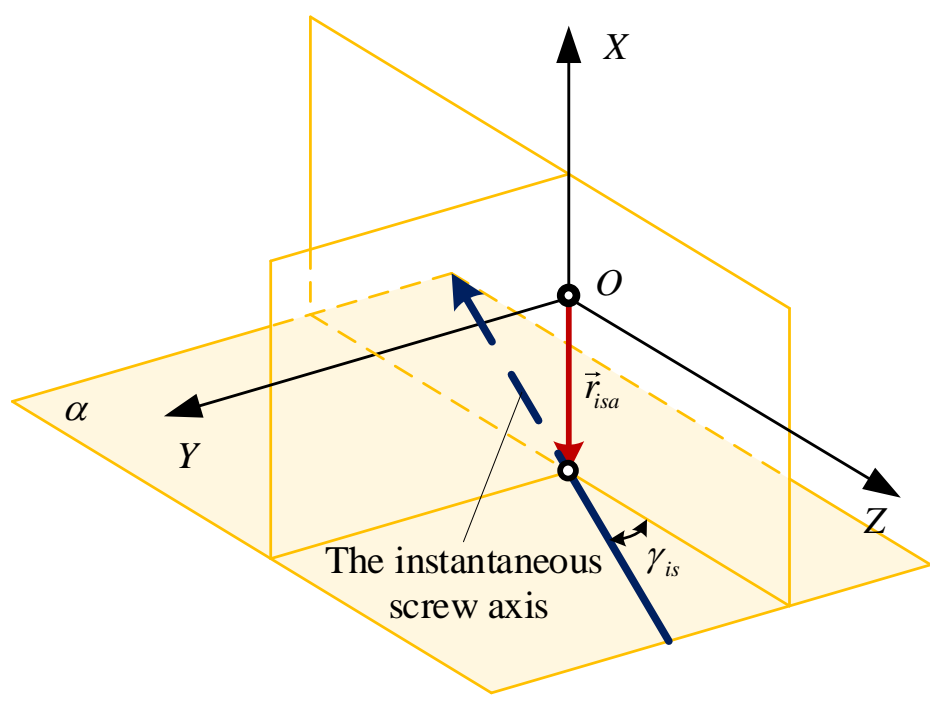

Figure 9. The spatial position and orientation of the instantaneous screw axis.

\subsubsection{Axodes}

Another important concept in gear kinematics is the axode, which is an important basic in gear design and manufacturing. The axodes are ruled surfaces that may be generated by an instantaneous screw axis in rotation about input and output axes with the I/O relationship varies, respectively [10]. A pair of instantaneous axodes can be used to transmit the conjugate motion of rolling and sliding between two axes.

The homogeneous transformation matrix $M_{1 f}$ from the fixed coordinate system $S$ to the input coordinate system $S_{1}$ is:

$$
M_{1 f}\left(\theta_{1}\right)=\left[\begin{array}{cc}
A_{1 f} & \vec{d}_{1 f} \\
\overrightarrow{0}^{T} & 1
\end{array}\right]=\left[\begin{array}{cccc}
\cos \theta_{1} & \sin \theta_{1} & 0 & 0 \\
-\sin \theta_{1} & \cos \theta_{1} & 0 & 0 \\
0 & 0 & 1 & 0 \\
0 & 0 & 0 & 1
\end{array}\right]
$$

The homogeneous transformation matrix $M_{2 f}$ from the fixed coordinate system $S$ to the output coordinate system $S_{2}$ is:

$$
M_{2 f}\left(\theta_{2}\right)=\left[\begin{array}{cc}
A_{2 f} & \vec{d}_{2 f} \\
\vec{T} & 1
\end{array}\right]=\left[\begin{array}{cccc}
\cos \theta_{2} & 0 & \sin \theta_{2} & 0 \\
-\sin \theta_{2} & 0 & \cos \theta_{2} & 0 \\
0 & -1 & 0 & -l\left(\theta_{1}\right) \\
0 & 0 & 0 & 1
\end{array}\right] .
$$

Therefore, the generators of the desired input $S_{a 1}$ and output $S_{a 2}$ axodes are determined as Equations (24) and (25), respectively.

$$
\begin{aligned}
S_{a 2} & =\left(\vec{C}_{a 2} ; \vec{\xi}_{a 2}\right)^{T}=\left(\left[A_{2 f}\right] \vec{C}_{i s} ;\left[A_{2 f}\right] \vec{\xi}_{i s}+\vec{d}_{2 f} \times\left[A_{2 f}\right] \vec{C}_{i s}\right)^{T} \\
& =-\omega_{1}\left[\sin \theta_{2}, \cos \theta_{2},-i\left(\theta_{1}\right) ; l\left(\theta_{1}\right) \cos \theta_{2},-l\left(\theta_{1}\right) \sin \theta_{2},-l \prime\left(\theta_{1}\right)\right]^{T}
\end{aligned}
$$




$$
\begin{aligned}
S_{a 1} & =\left(\vec{C}_{a 1} ; \vec{\xi}_{a 1}\right)^{T}=\left(\left[A_{1 f}\right] \vec{C}_{i s} ;\left[A_{1 f}\right] \vec{\xi}_{i s}+\vec{d}_{1 f} \times\left[A_{1 f}\right] \vec{C}_{i s}\right)^{T} \\
& =-\omega_{1}\left[i\left(\theta_{1}\right) \sin \theta_{1}, i\left(\theta_{1}\right) \cos \theta_{1}, 1 ; l^{\prime}\left(\theta_{1}\right) \sin \theta_{1}, l^{\prime}\left(\theta_{1}\right) \cos \theta_{1}, 0\right]^{T}
\end{aligned}
$$

As shown in Figure 10, these two axodes of the curve-face gear compound transmission are a pair of non-conical surfaces, which the unit is $\mathrm{mm}$.

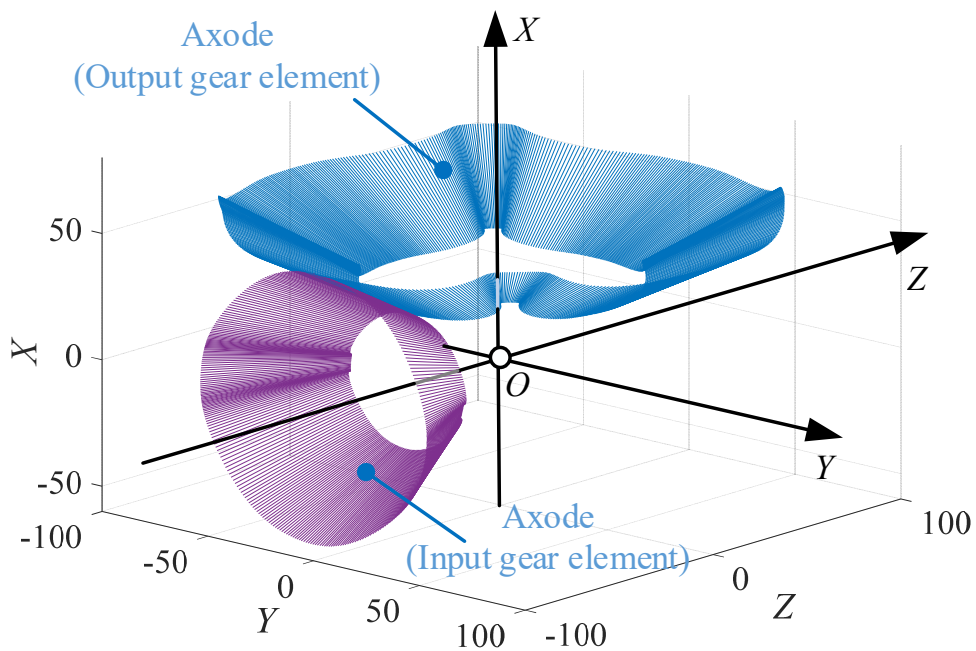

Figure 10. The axodes of the curve-face gear compound transmission.

\subsubsection{The Striction Curve}

The striction curve is an important and unique curve on the axode, which is the locus of common perpendiculars between successive generators, and it is also a reference curve to establish the geometric relationship between two axodes in mesh [13]. The input cylindrical gear is taken as the illustrative object, and the output gear is similar.

On the input axode, the screw $S_{\perp a 1}$ along the common perpendicular between the generator and its successive generator can be determined as

$$
S_{\perp a 1}=\left(\vec{C}_{\perp a 1} ; \vec{\xi}_{\perp a 1}\right)^{T}=\left(\vec{C}_{\perp a 1} \times{\overrightarrow{C^{\prime}}}_{a 1} ; \vec{C}_{\perp a 1} \times{\overrightarrow{\xi^{\prime}}}_{a 1}+\vec{\xi}_{\perp a 1} \times{\overrightarrow{C^{\prime}}}_{a 1}\right)^{T}
$$

Here, these derivatives $\vec{C}_{a 1}^{\prime}$ and $\vec{\xi}_{a 1}^{\prime}$ are relative to an arbitrary input displacement $\theta_{1}$. And the main vector $\vec{C}_{\perp a 1}$ and dual vector $\vec{\xi}_{\perp a 1}$ of the input screw $S_{\perp a 1}$ along the common perpendicular are:

$$
\vec{C}_{\perp a 1}=\omega_{1}^{2}\left[\begin{array}{c}
i\left(\theta_{1}\right) \sin \theta_{1}-i^{\prime}\left(\theta_{1}\right) \cos \theta_{1} \\
i\left(\theta_{1}\right) \cos \theta_{1}+i^{\prime}\left(\theta_{1}\right) \sin \theta_{1} \\
-i^{2}\left(\theta_{1}\right)
\end{array}\right]
$$

and

$$
\vec{\xi}_{\perp a 1}=\omega_{1}^{2}\left[\begin{array}{c}
l^{\prime}\left(\theta_{1}\right) \sin \theta_{1}-l^{\prime \prime}\left(\theta_{1}\right) \cos \theta_{1} \\
l^{\prime}\left(\theta_{1}\right) \cos \theta_{1}+l^{\prime \prime}\left(\theta_{1}\right) \sin \theta_{1} \\
-2 i\left(\theta_{1}\right) l^{\prime}\left(\theta_{1}\right)
\end{array}\right] .
$$

As the distribution parameter of the input axode, the pitch $h_{\perp a 1}$ of the input screw $S_{\perp a 1}$ along the common perpendicular can be obtained by:

$$
h_{\perp a 1}=\frac{\vec{C}_{\perp a 1} \cdot \vec{\zeta}_{\perp a 1}}{\vec{C}_{\perp a 1} \cdot \vec{C}_{\perp a 1}}=\frac{i\left(\theta_{1}\right) l^{\prime}\left(\theta_{1}\right)+i^{\prime}\left(\theta_{1}\right) l^{\prime \prime}\left(\theta_{1}\right)+2 i^{3}\left(\theta_{1}\right) l^{\prime}\left(\theta_{1}\right)}{i^{4}\left(\theta_{1}\right)+i^{2}\left(\theta_{1}\right)+i^{\prime 2}\left(\theta_{1}\right)}
$$

The loci of the intersection between the axis of $S_{\perp a 1}$ and the generator $S_{a 1}$ compose the striction curve. The coordinates $\vec{s}_{a 1}$ for the axode's striction curve can be expressed as: 


$$
\vec{s}_{a 1}=\vec{C}_{a 1} \times \vec{\xi}_{a 1}-\left[\vec{C}_{a 1} \cdot \vec{C}_{\perp a 1} \times\left(\vec{\xi}_{\perp a 1}-h_{\perp a 1} \cdot \vec{C}_{\perp a 1}\right)\right] \cdot \vec{C}_{a 1}=\omega_{1}^{2}\left[\begin{array}{c}
-l^{\prime}\left(\theta_{1}\right) \cos \theta_{1}+c_{1} i\left(\theta_{1}\right) \sin \theta_{1} \\
l^{\prime}\left(\theta_{1}\right) \sin \theta_{1}+c_{1} i\left(\theta_{1}\right) \cos \theta_{1} \\
-c_{1}
\end{array}\right]
$$

Here, $c_{1}=\omega_{1}^{4}\left\{\left[1+2 i^{2}\left(\theta_{1}\right)\right] i^{\prime}\left(\theta_{1}\right) l^{\prime}\left(\theta_{1}\right)-\left[1+i^{2}\left(\theta_{1}\right)\right] i\left(\theta_{1}\right) l^{\prime \prime}\left(\theta_{1}\right)\right\}$. Consequently, the equation of the axode's striction curve is:

$$
\vec{r}_{a 1}=\vec{s}_{a 1}+\omega_{1} \cdot \vec{C}_{a 1}=\omega_{1}^{2}\left[\begin{array}{c}
-l^{\prime}\left(\theta_{1}\right) \cos \theta_{1}+c_{1} i\left(\theta_{1}\right) \sin \theta_{1}-i\left(\theta_{1}\right) \sin \theta_{1} \\
l^{\prime}\left(\theta_{1}\right) \sin \theta_{1}+c_{1} i\left(\theta_{1}\right) \cos \theta_{1}-i\left(\theta_{1}\right) \cos \theta_{1} \\
-c_{1}-1
\end{array}\right]
$$

\section{Tooth Meshing Characteristics for Compound Transmission}

\subsection{Tooth Contact Analysis}

The tooth surface contact between the cylindrical gear and the curve-face gear in meshing without installation error will be explored. Similar to the generation of face gears, the number of shaper is more than that of cylindrical gear to maintain point contact between the surfaces of cylindrical gear and curve-face gear. The contact coordinate systems of tooth surfaces are established as shown in Figure 11, which is the same as the motion coordinate system. As shown in Figure 11, while cylindrical gear fixed inputs a rotation counterclockwise about Z-axis, the curve-face gear performs a screw motion clockwise with respect to the coordinate system $S$, and $Y$-axis is the axis of the screw motion.

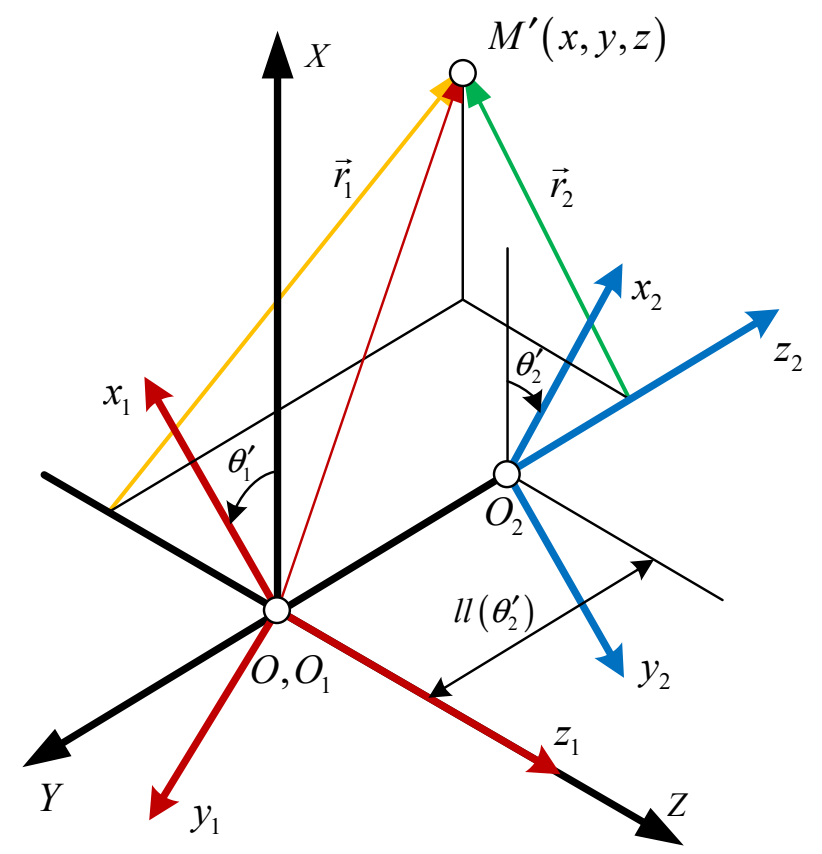

Figure 11. The contact coordinate systems of the curve-face gear compound transmission.

In this case, the left surfaces of cylindrical gear and curve-face gear are in meshing. As a result, the left tooth surface of the two input and output gears are taken as the explanation objects in this section, and the calculation method of the right tooth surfaces are similar.

By analogy to the equation of shaper tooth surface, the equation of the left involute cylindrical gear tooth surface in its rigidly connected coordinate system $S_{1}$ can be inferred, which the Gaussian coordinates $\left(\phi_{1}, u_{1}\right)$ are used to replace $\left(\phi_{s}, u_{s}\right)$. When the two gears in mesh, two tooth surfaces must be indeed in tangency with each other, so the position vector and normal vector of cylindrical gear coincide with those of the curve-face gear at any instant. The continuous tangency of contacting surfaces at the contact point $M^{\prime}$ are expressed by using the frame coordinate system $S$, and the relevant coordinate transforma- 
tion matrixes has been shown in Section 3.3. Consequently, using similar considerations, the position vector $\vec{r}_{1 L}^{(f)}$ and normal vector $\vec{n}_{1 L}^{(f)}$ of the cylindrical gear are derived in the coordinate system $S$ as:

$$
\vec{r}_{1 L}^{(f)}\left(\theta_{1}^{\prime}, \phi_{1}, u_{1}\right)=M_{f 1}\left(\theta_{1}^{\prime}\right) \vec{r}_{1 L}^{(1)}\left(\phi_{1}, u_{1}\right)=\left[\begin{array}{c}
r_{1}\left[\cos \left(\theta_{1}^{\prime}+\phi_{1}\right)+\left(\phi_{1}-\phi_{01}\right) \cos \alpha_{01} \sin \left(\theta_{1}^{\prime}+\phi_{1}-\alpha_{01}\right)\right] \\
r_{1}\left[\sin \left(\theta_{1}^{\prime}+\phi_{1}\right)-\left(\phi_{1}-\phi_{01}\right) \cos \alpha_{01} \cos \left(\theta_{1}^{\prime}+\phi_{1}-\alpha_{01}\right)\right] \\
u_{1} \\
1
\end{array}\right]
$$

and

$$
\vec{n}_{1 L}^{(f)}\left(\theta_{1}^{\prime}, \phi_{1}, u_{1}\right)=M_{f 1}\left(\theta_{1}^{\prime}\right) \vec{n}_{1 L}^{(1)}\left(\phi_{1}, u_{1}\right)=\left[\begin{array}{c}
-\sin \left(\theta_{1}^{\prime}+\phi_{1}-\alpha_{01}\right) \\
\cos \left(\theta_{1}^{\prime}+\phi_{1}-\alpha_{01}\right) \\
0 \\
1
\end{array}\right]
$$

And the position vector $\vec{r}_{2 L}^{(f)}$ and normal vector $\vec{n}_{2 L}^{(f)}$ of the curve-face gear can be represented in the coordinate system $S$ as follows:

$$
\begin{gathered}
\vec{r}_{2 L}^{(f)}\left(\theta_{2}^{\prime}, \phi_{s}, u_{s}\right)=M_{f 2}\left(\theta_{2}^{\prime}\right) \vec{r}_{2 L}^{(2)}\left(\phi_{s}, u_{s}\right) \\
=\left[\begin{array}{c}
r_{s} \cos \left(\theta_{2}-\theta_{2}^{\prime}\right)\left[\cos \left(\theta_{s}+\phi_{s}\right)+\left(\phi_{s}-\phi_{0 s}\right) \cos \alpha_{0 s} \sin \left(\theta_{s}+\phi_{s}-\alpha_{0 s}\right)\right]+\sin \left(\theta_{2}-\theta_{2}^{\prime}\right) u_{s}\left(\theta_{s}, \phi_{s}\right) \\
r_{s}\left[\sin \left(\theta_{s}+\phi_{s}\right)-\left(\phi_{s}-\phi_{0 s}\right) \cos \alpha_{0 s} \cos \left(\theta_{s}+\phi_{s}-\alpha_{0 s}\right)\right]+l\left(\theta_{2}\right)-l l\left(\theta_{1}^{\prime}\right) \\
-r_{s} \sin \left(\theta_{2}-\theta_{2}^{\prime}\right)\left[\cos \left(\theta_{s}+\phi_{s}\right)+\left(\phi_{s}-\phi_{0 s}\right) \cos \alpha_{0 s} \sin \left(\theta_{s}+\phi_{s}-\alpha_{0 s}\right)\right]+\cos \left(\theta_{2}-\theta_{2}^{\prime}\right) u_{s}\left(\theta_{s}, \phi_{s}\right) \\
1
\end{array}\right] \\
\text { and } \\
\vec{n}_{2 L}^{(f)}\left(\theta_{2}^{\prime}, \phi_{s}, u_{s}\right)=M_{f 2}\left(\theta_{2}^{\prime}\right) M_{2 s}\left(\theta_{s}\right) \vec{n}_{2 L}^{(2)}\left(\phi_{s}, u_{s}\right)=\left[\begin{array}{c}
-\cos \left(\theta_{2}-\theta_{2}^{\prime}\right) \sin \left(\theta_{s}+\phi_{s}-\alpha_{0 s}\right) \\
\cos \left(\theta_{s}+\phi_{s}-\alpha_{0 s}\right)+l\left(\theta_{2}\right)-l l\left(\theta_{1}^{\prime}\right) \\
-\sin \left(\theta_{2}-\theta_{2}^{\prime}\right) \sin \left(\theta_{s}+\phi_{s}-\alpha_{0 s}\right) \\
1
\end{array}\right],
\end{gathered}
$$

where, $\theta_{1}^{\prime}$ and $\theta_{2}^{\prime}$ are correspondingly the angular displacements of the cylindrical gear and the curve-face gear in meshing.

When $\theta_{2}^{\prime}$ is taken as the input parameter, then the vector equations of tangency of contacting surfaces can be described as:

$$
\left\{\begin{array}{l}
r_{1}\left[\cos \left(\theta_{1}^{\prime}+\phi_{1}\right)+\left(\phi_{1}-\phi_{01}\right) \cos \alpha_{01} \sin \left(\theta_{1}^{\prime}+\phi_{1}-\alpha_{01}\right)\right] \ldots \\
=r_{s} \cos \left(\theta_{2}-\theta_{2}^{\prime}\right)\left[\cos \left(\theta_{s}+\phi_{s}\right)+\left(\phi_{s}-\phi_{0 s}\right) \cos \alpha_{0 s} \sin \left(\theta_{s}+\phi_{s}-\alpha_{0 s}\right)\right]+\sin \left(\theta_{2}-\theta_{2}^{\prime}\right) u_{s}\left(\theta_{s}, \phi_{s}\right) \\
r_{1}\left[\sin \left(\theta_{1}^{\prime}+\phi_{1}\right)-\left(\phi_{1}-\phi_{01}\right) \cos \alpha_{01} \cos \left(\theta_{1}^{\prime}+\phi_{1}-\alpha_{01}\right)\right] \ldots \\
=r_{s}\left[\sin \left(\theta_{s}+\phi_{s}\right)-\left(\phi_{s}-\phi_{0 s}\right) \cos \alpha_{0 s} \cos \left(\theta_{s}+\phi_{s}-\alpha_{0 s}\right)\right]+l\left(\theta_{2}\right)-l l\left(\theta_{1}^{\prime}\right) \\
\sin \left(\theta_{1}^{\prime}+\phi_{1}-\alpha_{01}\right)=\cos \left(\theta_{2}-\theta_{2}^{\prime}\right) \sin \left(\theta_{s}+\phi_{s}-\alpha_{0 s}\right) \\
\cos \left(\theta_{1}^{\prime}+\phi_{1}-\alpha_{01}\right)=\cos \left(\theta_{s}+\phi_{s}-\alpha_{0 s}\right)+l\left(\theta_{2}\right)-l l\left(\theta_{1}^{\prime}\right) \\
0=-\sin \left(\theta_{2}-\theta_{2}^{\prime}\right) \sin \left(\theta_{s}+\phi_{s}-\alpha_{0 s}\right)
\end{array}\right.
$$

It is easy to verify that, while the two tooth surfaces are indeed in tangency with each other, the angular displacement $\theta_{2}$ of curve-face gear being generated is equal to its angular displacement $\theta_{2}^{\prime}$ for compound transmission. And the angular displacement $\theta_{1}^{\prime}$ of the cylindrical gear for compound transmission can obtained based on the desired gear ratio as:

$$
\theta_{1}^{\prime}\left(\theta_{2}^{\prime}\right)=\frac{\int_{0}^{\theta_{2}^{\prime}} \sqrt{R^{2}+l l^{\prime 2}(\theta)} d \theta}{r_{1}}
$$

The angular displacement $\theta_{s}\left(\theta_{2}^{\prime}\right)$ of shaper is:

$$
\theta_{s}\left(\theta_{2}^{\prime}\right)=\frac{\int_{0}^{\theta_{2}^{\prime}} \sqrt{R^{2}+l^{\prime 2}(\theta)} d \theta}{r_{s}}
$$


Thus, the Gaussian coordinates $\left[\phi_{s}\left(\theta_{2}^{\prime}\right), u_{s}\left(\theta_{2}^{\prime}\right)\right]$ of the involute shaper surface is represented by implicit function:

$$
\left\{\begin{array}{l}
p\left(\phi_{s}\right)=\left(r_{1}-r_{s}\right) \sin \left(\theta_{s}+\phi_{s}\right)-\left[r_{b 1}\left(\phi_{s}-\phi_{01}+\theta_{s}-\theta_{1}^{\prime}\right)-r_{b s}\left(\phi_{s}-\phi_{0 s}\right)\right] \cos \left(\theta_{s}+\phi_{s}-\alpha_{0 s}\right)=0 \\
u_{s}\left(\theta_{2}^{\prime}\right)=\frac{r_{b s}+i_{2 s}\left(\theta_{2}\right) l^{\prime}\left(\theta_{2}\right) \cos \left(\theta_{s}+\phi_{s}-\alpha_{0 s}\right)}{i_{2 s}\left(\theta_{2}\right) \sin \left(\theta_{s}+\phi_{s}-\alpha_{0 s}\right)}
\end{array}\right.
$$

And the Gaussian coordinates $\left[\phi_{1}\left(\theta_{2}^{\prime}\right), u_{1}\left(\theta_{2}^{\prime}\right)\right]$ of the cylindrical gear surface is:

$$
\left\{\begin{array}{l}
q\left(\phi_{s}\right)=\left(r_{1}-r_{s}\right) \sin \left(\theta_{1}^{\prime}+\phi_{1}\right)-\left[r_{b 1}\left(\phi_{1}-\phi_{01}\right)-r_{b s}\left(\phi_{1}-\phi_{0 s}+\theta_{1}^{\prime}-\theta_{s}\right)\right] \cos \left(\theta_{1}^{\prime}+\phi_{1}-\alpha_{0 s}\right)=0 \\
u_{s}\left(\theta_{2}^{\prime}\right)=\frac{r_{b s}+i_{2 s}\left(\theta_{2}\right) l^{\prime}\left(\theta_{2}\right) \cos \left(\theta_{s}+\phi_{s}-\alpha_{0 s}\right)}{i_{2 s}\left(\theta_{2}\right) \sin \left(\theta_{s}+\phi_{s}-\alpha_{0 s}\right)}
\end{array}\right.
$$

As a result, the contact path on the cylindrical gear surfaces and the curve-face gear surfaces can be determined by $\vec{r}_{1 L}^{(1)}\left[\phi_{1}\left(\theta_{2}^{\prime}\right), u_{1}\left(\theta_{2}^{\prime}\right)\right]$ and $\vec{r}_{2 L}^{(2)}\left[\theta_{s}\left(\theta_{2}^{\prime}\right), \phi_{s}\left(\theta_{2}^{\prime}\right)\right]$, respectively. The contact paths of the meshing area for the cylindrical gear and the curve-face gear on each tooth surface in a meshing cycle is visualized by MATLAB, as shown in Figure 12 below, which the units of contact paths are $\mathrm{mm}$.

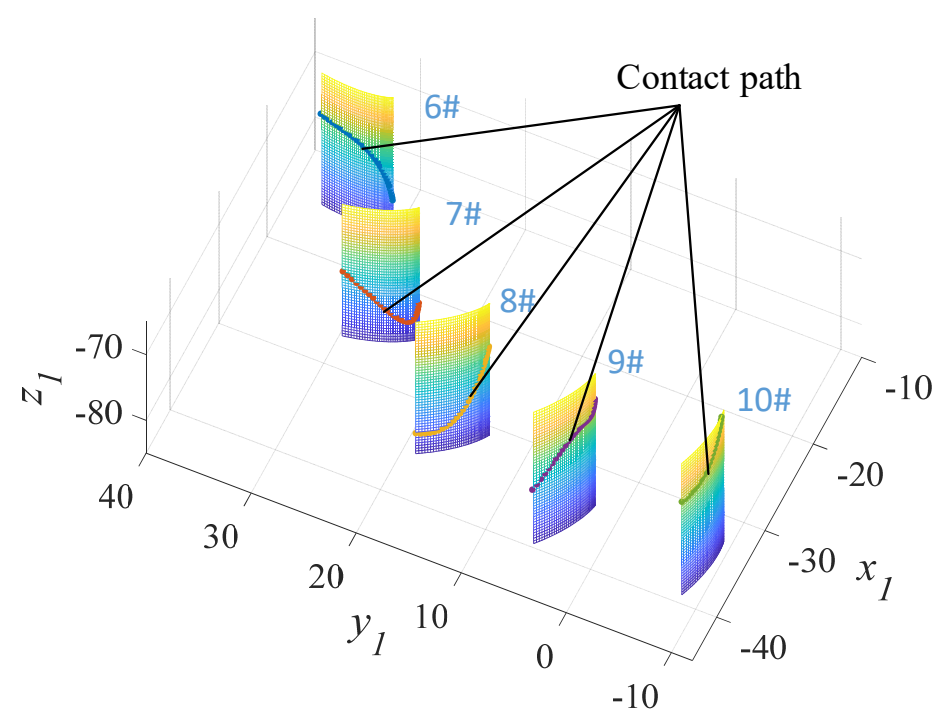

(a) The cylindrical gear surfaces.

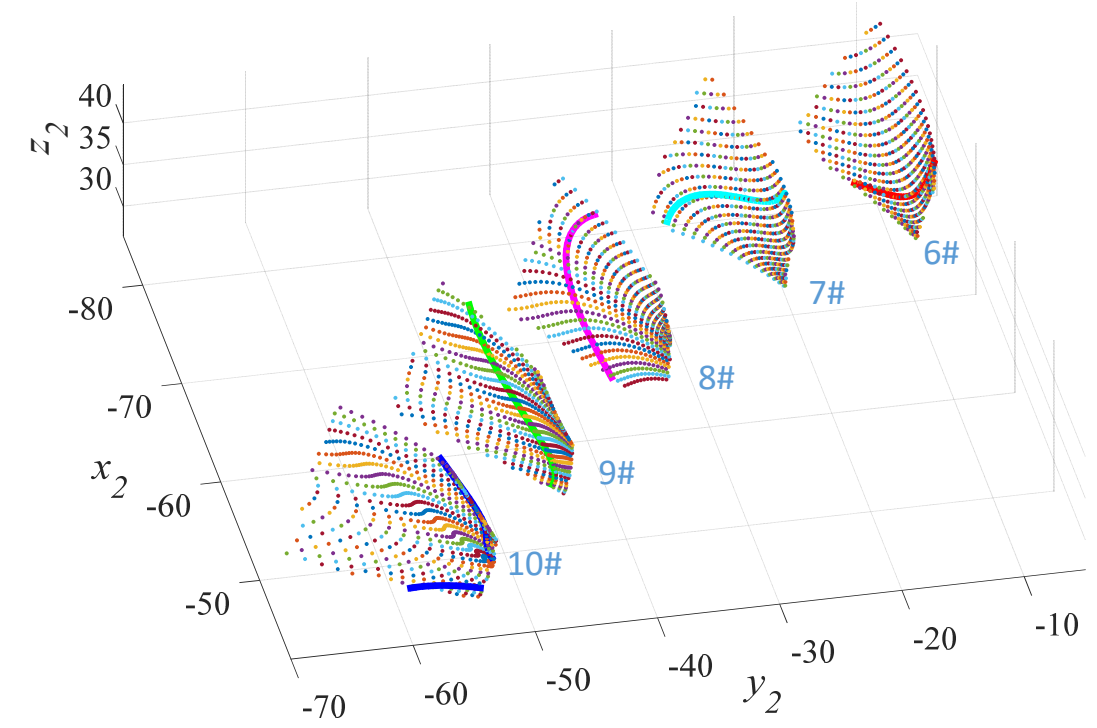

(b) The curve-face gear surfaces.

Figure 12. The contact path on the cylindrical gear surfaces and the curve-face gear surfaces. 
It can be seen from Figure 12, due to the difference of each tooth surfaces of curve-face gear, the contact path of each tooth is also different when it engages with the cylindrical gear in direct contact. Moreover, when the cylindrical gear with different gear number engages with the same curve-face gear, the contact traces on the two gear tooth surfaces are also different.

\subsection{Reciprocity}

We have to emphasize the reciprocity of curve-face gear compound transmission, because the conjugate action is defined as the reciprocity between the common normal to two tooth surfaces and the instantaneous screw at the contact point when the gear pair teeth are engaged.

The common normal screw $S_{l}\left(\theta_{2}^{\prime}\right)$ to tooth surfaces in contact of the curve-face gear compound transmission pair is represented in $S$ by:

$$
S_{l}\left(\theta_{2}^{\prime}\right)=\left(\begin{array}{c}
\vec{C}_{l} \\
\vec{\xi}_{l}
\end{array}\right)=\left(\begin{array}{c}
\vec{n}_{1 L}^{(f)}\left(\theta_{2}^{\prime}\right) \\
\vec{r}_{1 L}^{(f)}\left(\theta_{2}^{\prime}\right) \times \vec{n}_{1 L}^{(f)}\left(\theta_{2}^{\prime}\right)
\end{array}\right)=\left(\begin{array}{c}
-\sin \left(\theta_{1}^{\prime}+\phi_{1}-\alpha_{0}\right) \\
\cos \left(\theta_{1}^{\prime}+\phi_{1}-\alpha_{0}\right) \\
0 \\
-u_{1}\left(\theta_{2}^{\prime}\right) \cos \left(\theta_{1}^{\prime}+\phi_{1}-\alpha_{0}\right) \\
-u_{1}\left(\theta_{2}^{\prime}\right) \sin \left(\theta_{1}^{\prime}+\phi_{1}-\alpha_{0}\right) \\
r_{1} \cos \alpha_{0}
\end{array}\right) .
$$

When $\theta_{2}^{\prime}$ is also taken as the input parameter, it is obvious that the instantaneous twist $S_{\text {is }}\left(\theta_{2}^{\prime}\right)$ equation:

$$
S_{i s}\left(\theta_{2}^{\prime}\right)=\left(\begin{array}{c}
{\overrightarrow{C_{i s}}}_{\overrightarrow{\xi_{i s}}} \\
\overrightarrow{\xi_{i s}}
\end{array}\right)=\left[0,-1,-1 / i_{21}\left(\theta_{2}^{\prime}\right) ; 0,-l l^{\prime}\left(\theta_{2}^{\prime}\right), 0\right]^{T} .
$$

of the curve-face gear compound transmission can be applied instead of Equation (18).

Consequently, the reciprocal product (virtual coefficient) between the common normal to two tooth surfaces and the instantaneous screw at the contact point is zero as follow.

$$
\begin{gathered}
S_{l}\left(\theta_{2}^{\prime}\right) \circ S_{i s}\left(\theta_{2}^{\prime}\right)=\vec{C}_{l} \cdot \vec{\xi}_{i s}+\vec{C}_{i s} \cdot \vec{\xi}_{l}= \\
0 \\
{\left[\begin{array}{c}
-\sin \left(\theta_{1}^{\prime}+\phi_{1}-\alpha_{0}\right) \\
\cos \left(\theta_{1}^{\prime}+\phi_{1}-\alpha_{0}\right)
\end{array}\right] \cdot\left[\begin{array}{c}
0 \\
-l l^{\prime}\left(\theta_{2}^{\prime}\right) \\
0
\end{array}\right]+\left[\begin{array}{c}
0 \\
-1 \\
-1 / i_{21}\left(\theta_{2}^{\prime}\right)
\end{array}\right]} \\
{\left[\begin{array}{c}
-u_{1}\left(\theta_{2}^{\prime}\right) \cos \left(\theta_{1}^{\prime}+\phi_{1}-\alpha_{0}\right) \\
-u_{1}\left(\theta_{2}^{\prime}\right) \sin \left(\theta_{1}^{\prime}+\phi_{1}-\alpha_{0}\right) \\
r_{1} \cos \alpha_{0}
\end{array}\right]=0 .}
\end{gathered}
$$

As the reciprocal product of the common normal and the instantaneous screw is zero, it can be identified that the curve-face gear compound transmission can realize the conjugate action with expected instantaneous transmission ratio, which satisfies the first law of gearing [13].

\subsection{Relative Displacements Sectioetween Conjugate Gear Surfaces}

As mentioned earlier, there is no pure roll in any spatial position of the curve-face gear compound transmission. That is, relative motion exists between the contact points on the conjugate surfaces, and the velocities of two contact points differ in both magnitude and direction. Therefore, it is necessary to discuss the sliding velocity and rolling velocity of the curve-face gear compound transmission pair at the contact point. Additionally, the relative displacement at the contact point is independent of the input and output displacements.

The sliding velocity $\vec{v}_{s}$ is the relative motion velocity between two conjugate surfaces and affects the loss of gear meshing directly. The rolling velocity $\vec{v}_{r}$ is used to measure the speed at which the lubricating oil enters the mesh. 
In the fixed coordinate system $S$, along the line of action $\underline{\Phi}_{l}$, the velocity of the cylindrical gear $\vec{v}_{m 1}^{(f)}$ and the curve-face gear $\vec{v}_{m 2}^{(f)}$ at the conjugate contact point $M^{\prime}$ can be resolved into $\vec{v}_{\| m 1}(f), \vec{v}_{\perp m 1}(f)$ and $\vec{v}_{\| m 2}(f), \vec{v}_{\perp m 2}$, respectively. Due to the conjugate action of the curve-face gear compound transmission, the parallel components $\vec{v}_{\| m 1}^{(f)}$ and $\vec{v}_{\| m 2}^{(f)}$ of contact points on the two tooth surfaces are equal with each other. Then, the sliding velocity $\vec{v}_{s}$ of the curve-face gear compound transmission pair is:

$$
\vec{v}_{s}=\vec{v}_{\perp m 1}^{(f)}-\vec{v}_{\perp m 2}^{(f)}
$$

And the rolling velocity $\vec{v}_{r}$ is expressed by:

$$
\vec{v}_{r}=\frac{1}{2}\left(\vec{v}_{\perp m 1}^{(f)}+\vec{v}_{\perp m 2}^{(f)}\right)
$$

The velocity of the cylindrical gear $\vec{v}_{m 1}^{(f)}$ and the curve-face gear $\vec{v}_{m 2}^{(f)}$ at the conjugate contact point $M^{\prime}$ in the fixed coordinate system $S$ may be represented using Equations (46) and (47).

$$
\begin{aligned}
\vec{v}_{m 1}^{(f)}=\vec{\omega}_{1} \times \vec{r}_{1 L}^{(f)}=r_{1} \omega_{1}\left[\begin{array}{c}
-\sin \left(\theta_{1}^{\prime}+\phi_{1}\right)+\left(\phi_{1}-\phi_{01}\right) \cos \alpha_{0} \cos \left(\theta_{1}^{\prime}+\phi_{1}-\alpha_{0}\right) \\
\cos \left(\theta_{1}^{\prime}+\phi_{1}\right)+\left(\phi_{1}-\phi_{01}\right) \cos \alpha_{0} \sin \left(\theta_{1}^{\prime}+\phi_{1}-\alpha_{0}\right) \\
0
\end{array}\right] \\
\vec{v}_{m 2}^{(f)}=\vec{\omega}_{2} \times \vec{r}_{2 L}^{(f)}+\vec{v}_{0}^{(f)} \\
=\omega_{2}\left[\begin{array}{c}
u_{s}\left(\theta_{s}, \phi_{s}\right) \\
-l l\left(\theta_{1}^{\prime}\right) \\
r_{s}\left[\cos \left(\theta_{s}+\phi_{s}\right)+\left(\phi_{s}-\phi_{0 s}\right) \cos \alpha_{0} \sin \left(\theta_{s}+\phi_{s}-\alpha_{0}\right)\right]
\end{array}\right]
\end{aligned}
$$

Therefore, the perpendicular components $\vec{v}_{\perp m 1}^{(f)}$ and $\vec{v}_{\perp m 2}^{(f)}$ of the cylindrical gear and the curve-face gear (perpendicular to the line of action $\Phi_{l}$ ) are:

$$
\vec{v}_{\perp m 1}^{(f)}=\vec{C}_{l} \times\left(\vec{v}_{m 1}^{(f)} \times \vec{C}_{l}\right)=r_{1} \omega_{1}\left[-\sin \alpha_{0}+\left(\phi_{1}-\phi_{01}\right) \cos \alpha_{0}\right]\left[\begin{array}{c}
\cos \left(\theta_{1}^{\prime}+\phi_{1}-\alpha_{0}\right) \\
\sin \left(\theta_{1}^{\prime}+\phi_{1}-\alpha_{0}\right) \\
0
\end{array}\right]
$$

and

$$
\vec{v}_{\perp m 2}^{(f)}=\vec{C}_{l} \times\left(\vec{v}_{m 2}^{(f)} \times \vec{C}_{l}\right)=\omega_{2}\left[\begin{array}{c}
\cos ^{2}\left(\theta_{1}^{\prime}+\phi_{1}-\alpha_{0}\right) u_{s}\left(\theta_{s}, \phi_{s}\right)-\sin \left(\theta_{1}^{\prime}+\phi_{1}-\alpha_{0}\right) \cos \left(\theta_{1}^{\prime}+\phi_{1}-\alpha_{0}\right) l l\left(\theta_{1}^{\prime}\right) \\
\sin ^{2}\left(\theta_{1}^{\prime}+\phi_{1}-\alpha_{0}\right) l l\left(\theta_{1}^{\prime}\right)+\sin \left(\theta_{1}^{\prime}+\phi_{1}-\alpha_{0}\right) \cos \left(\theta_{1}^{\prime}+\phi_{1}-\alpha_{0}\right) u_{s}\left(\theta_{s}, \phi_{s}\right) \\
r_{s}\left[\cos \left(\theta_{s}+\phi_{s}\right)+\left(\phi_{s}-\phi_{0 s}\right) \cos \alpha_{0} \sin \left(\theta_{s}+\phi_{s}-\alpha_{0}\right)\right]
\end{array}\right] .
$$

Based on the above equations, the sliding velocity $\vec{v}_{s}$ and the rolling velocity $\vec{v}_{r}$ of the contact points on each tooth in a cycle can be depicted in Figure 13.

As shown in Figure 13, the relative sliding velocity $\vec{v}_{s}$ of the contact points on each tooth in a cycle decreases gradually with the increase of the angular displacement $\theta_{1}$ of cylindrical gear in the process of motion. There exist two extremes of the relative sliding velocity $\vec{v}_{s}$ when teeth engaging and disengaging in contact. Although the sliding velocity on each gear tooth is different, but the sliding velocity variation range is similar. The rolling velocity $\vec{v}_{r}$ of the contact points on each tooth in a cycle first decreases and then increases with the increase of the angular displacement $\theta_{1}$ of cylindrical gear in the process of motion, and the variation range of rolling velocity is also similar. It is obvious that there is no contact point with a pure roll in the process of the curve-face gear compound motion, and rolling and sliding action will coexist at any contact position on the tooth surfaces. 


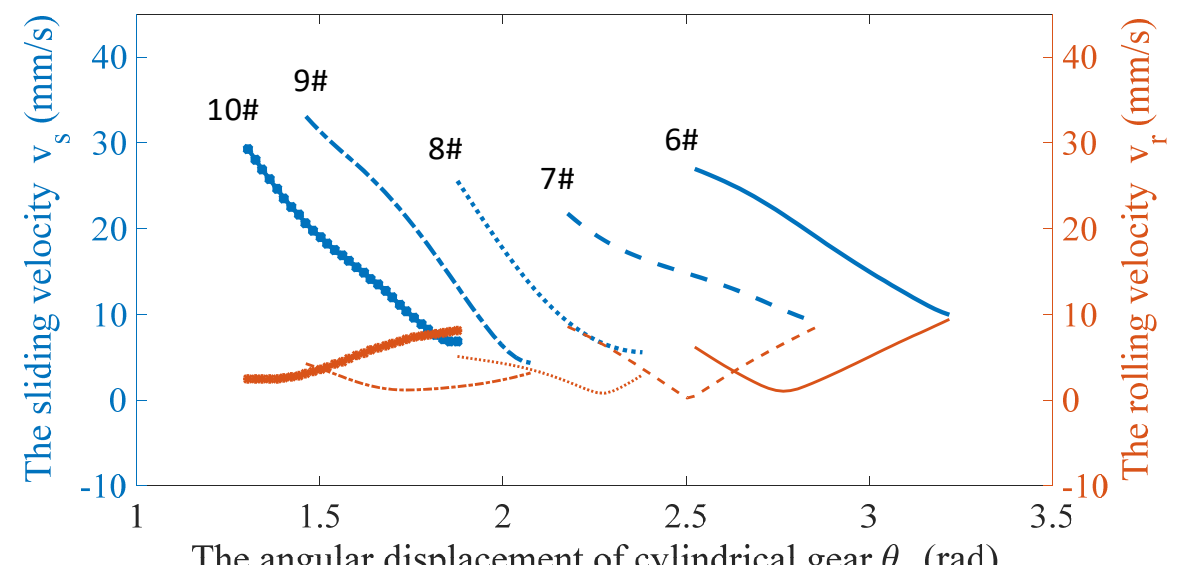

Figure 13. Relative displacements of conjugate gear surfaces.

\section{Geometrical Measurement by Tooth Surface}

In this section, in order to verify the correctness of the mathematical method for tooth surface modeling, the curve-face gear was processed by milling using DMU60monoBLOCK five-axis CNC machining [43], which is produced by Deckel Maho Gildemeister Group (DMG) in Germany. In addition, the material of curve-face gear and cylindrical gear both are $40 \mathrm{Cr}$. Then, the geometry of tooth surface was measured by the gear testing center, and the machining accuracy of the tooth surface compared with the mathematical modeling was analyzed. And the geometry parameters of curve-face gear pair are shown in Table 2.

Table 2. Geometry parameters of curve-face gear pair.

\begin{tabular}{ll}
\hline Parameters & Values \\
\hline Module $m(\mathrm{~mm})$ & 4 \\
Number of cylindrical gear $z_{1}$ & 18 \\
Number of curve-face gear $z_{2}$ & 36 \\
Order of curve-face gear $n_{2}$ & 4 \\
Inner radius of the curve-face gear $R_{1}(\mathrm{~mm})$ & 70 \\
Outer radius of the curve-face gear $R_{2}(\mathrm{~mm})$ & 83 \\
\hline
\end{tabular}

Due to the complexity in geometry of tooth surface, the method of simulation machining was adopted for modeling of curve-face gear in our previous works. This modeling process mainly utilized the secondary development tool VBA of SolidWorks and can be described briefly below: firstly, the non-circular shaper used to process the curve-face gear is designed; secondly, the rough model of curve-face gear is obtained as simulating the process of generation by the non-circular shaper; finally, the smooth curve-face gear model is obtained after finishing the tooth surface using the cross-section method [44]. However, mathematical method is used in this paper, which seems to be more efficient and simpler than the method of simulation machining. Similarly, the detailed steps of mathematical method are as follows: firstly, discrete point data of tooth surface is acquired by MATLAB according to the equation of curve-face gear tooth surface; secondly, these discrete point data are scanned by the scanto3D function of SolidWorks and converted into the solid model of the tooth surface; finally, smooth tooth surface and solid model of the gear tooth will be further obtained by adjusting the scanned parameters of SolidWorks.

Figure 14 shows the comparison of the rough models of tooth surfaces by above two methods. Obviously, the initial tooth surface model, before finishing of mathematical method, is smoother, and final tooth surface and gear tooth solid model can be obtained directly only by changing the parameters of Scanto3D. In comparison with the method of simulation machining, mathematical method can realize the modeling of the curve-face gear exactly and quickly. 


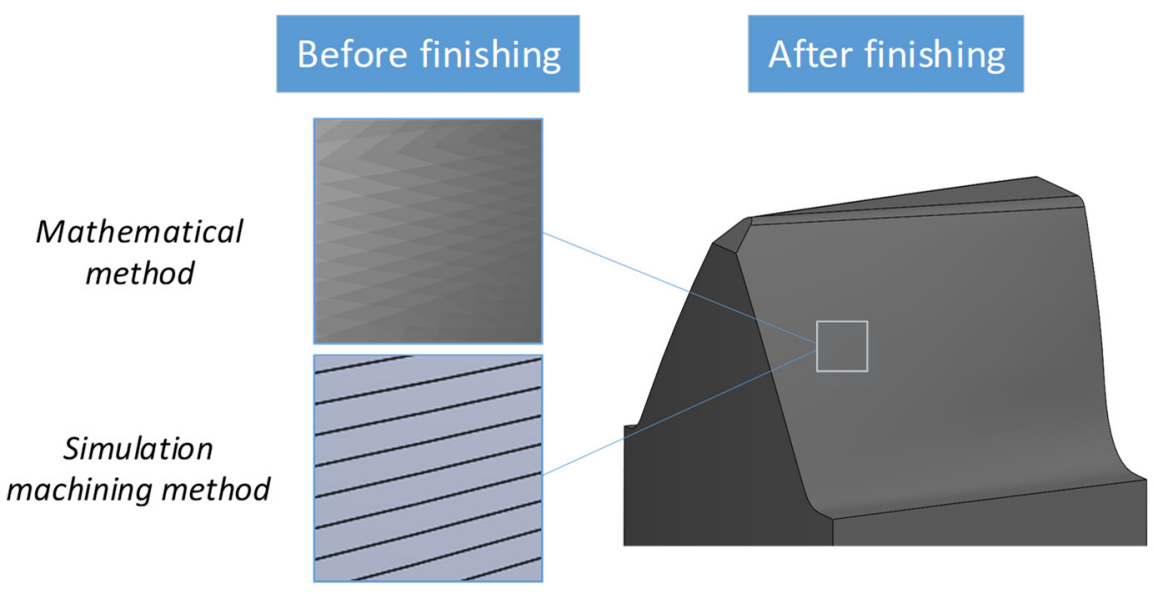

Figure 14. The curve-face gear surface by mathematical method compared with simulation machining method.

The five-axis CNC machining center is used to process the final curve-face gear elements, as shown in Figure 15a. The P26 Automatic CNC Control Gear Testing Center from Klingelnberg Company in Germany is selected to carry out geometric measurement of the tooth surface, as shown in Figure 15b.

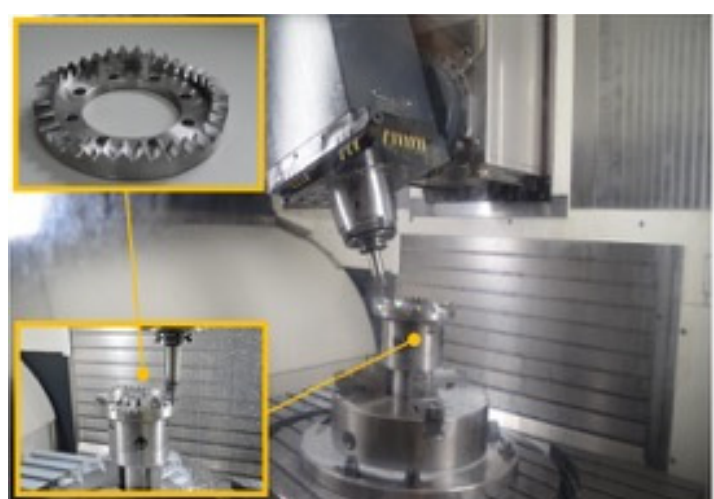

(a)

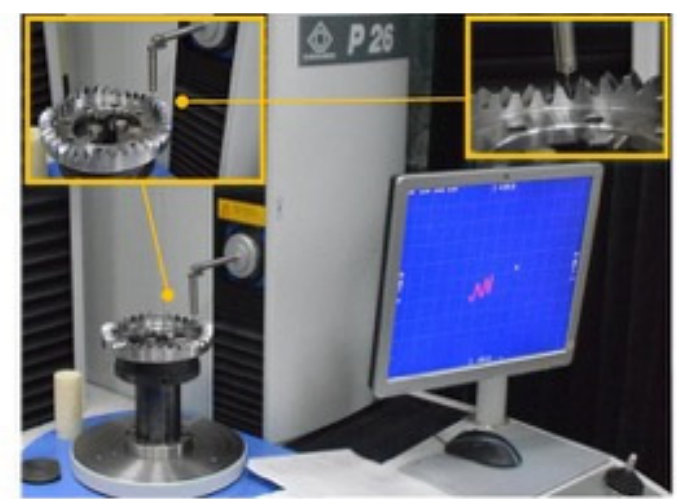

(b)

Figure 15. The machining and measuring process of the curve-face gear element. (a) The machining process; (b) The measuring process.

Based on the formula for tooth relative error of gear tooth [45], 10\# gear tooth shown in Figure 5 in Section 2.2 is selected and studied. The data points on 10\# gear tooth are extracted by the grid, and the relative error analysis of curve-face gear is depicted in Figure 16, and the unit of the relative error is $\mu \mathrm{m}$.

Using the simulation machining method, the accuracy detection of the tooth surface is performed on the curve-face gear model after finishing, regardless of the model error during finishing. As a consequence, the tooth relative error of machined gear is mainly caused by manufacturing not the actual tooth surface relative error. In contrast, during the accuracy detection of tooth surface obtained by mathematical method, the theoretical coordinate of points on the tooth surface is obtained by MATLAB, which is the real theoretical model of curve-face gear. Due to the consideration of the machining model error after simulation finishing, the actual relative error of the gear tooth surface can be obtained more accurately. 


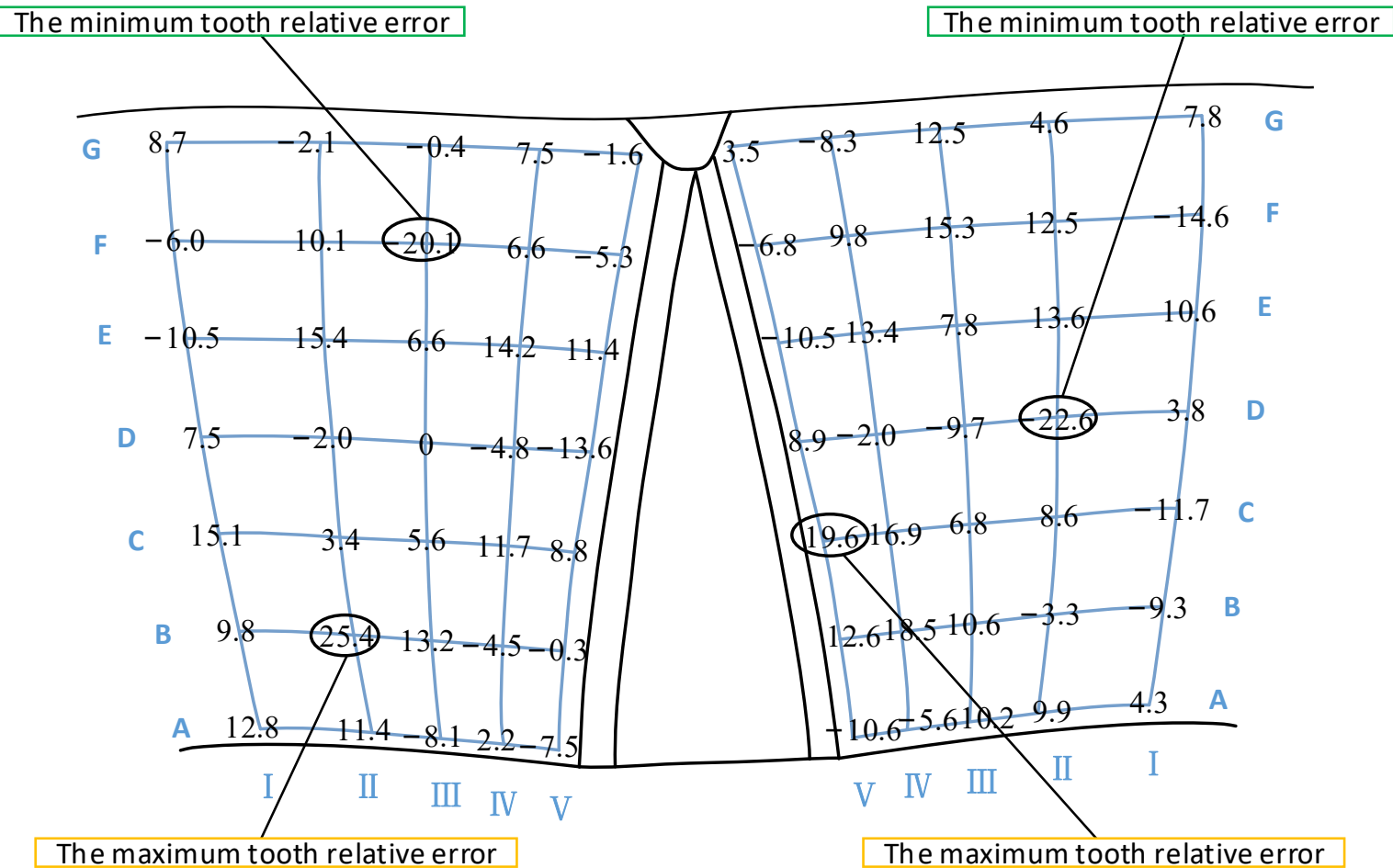

Figure 16. The analysis of the relative error result of curve-face gear.

$e_{0}$ and $e_{n}$ represent the interval length of a tooth surface relative error obtained by simulation machining method in our previous research $[44,46]$ and mathematical method in current work, respectively. The maximum and minimum relative error $\varepsilon_{n \max }$ and $\varepsilon_{n \min }$ of the left curve-face gear tooth surface in a meshing cycle can also be obtained. Then, the difference value $e$ between $e_{0}$ and $e_{n}$ as well as the values of above parameters are also present in Figure 17.

It can be seen from Figure 17, the variation range of $\varepsilon_{n \max }$ is from $24.4 \mu \mathrm{m}$ to $29.4 \mu \mathrm{m}$, the accuracy grade is 9 th. The variation range of $\varepsilon_{\text {nmin }}$ is from $-21.5 \mu \mathrm{m}$ to $-16.9 \mu \mathrm{m}$, and the accuracy grade is 8 th. The relative error of each tooth surface are similar with the other tooth surfaces in a same meshing cycle, and the accuracy of tooth surfaces also are identical with each other. The comparison between the interval lengths of relative errors obtained by the two methods is from $6.5 \mu \mathrm{m}$ to $9.9 \mu \mathrm{m}$. This is caused by which the value of sketched point is often larger than the theoretical value in the process of simulation finishing. Therefore, considering the error of modeling, the accuracy grade of the tooth surface is 9 th, which can evaluate the tooth surface of curve-face gear more accurately.

In order to obtain the meshing area and actual contact results of the tooth surface of the curve-face gear, the transmission test platform was designed as shown in Figure 18a, and red lead powder is applied to the tooth surface of the gear pair. After meshing and transmission, the contact area on 1\#-4\# tooth surfaces as shown in Figure $18 \mathrm{~b}$ were obtained, that is, the part with red lead powder worn off. 


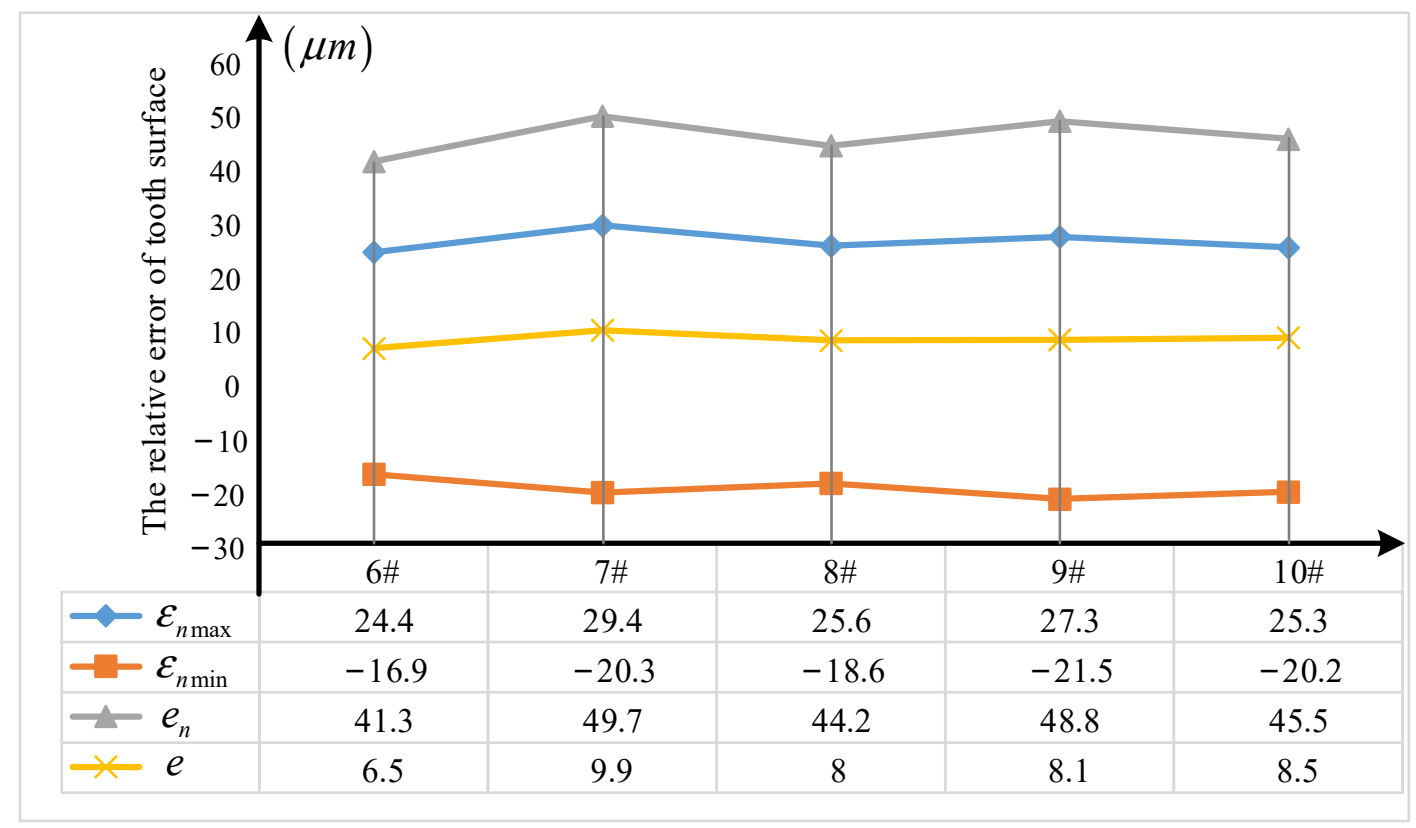

Figure 17. The relative error of tooth surface in a meshing cycle.

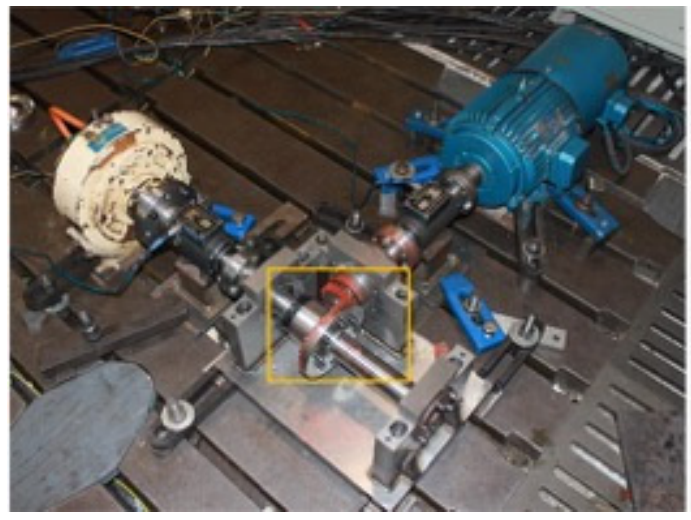

(a) Transmission test platform

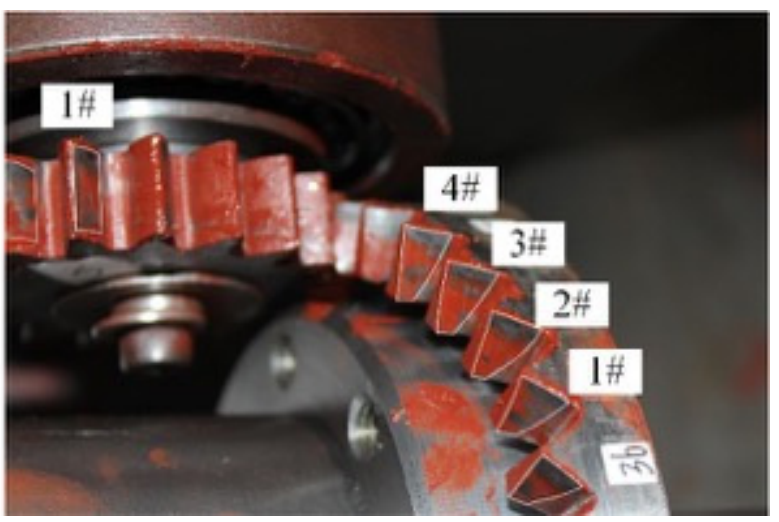

(b) Contact results of the tooth surface

Figure 18. The experimental results of meshing evaluation for curve-face gear pair.

After the cylindrical gear with the same number of teeth as the gear shaper cutter rolling with the curve-face gear for a period of time, the instantaneous contact line forms a stable contact area on the tooth surface. When two or more teeth are in contact at the same time, the contact line shows an inclined straight line on the curve-face gear surface, which is very obvious in the contact after the load applied. And the contact area is basically unchanged in the process from trough to peak and from peak to trough, which finally forms the contact area in Figure 18b. By comparing the actual contact area with the theoretical contact line in Figure 5, it is found that the theory is basically consistent with the practice.

\section{Conclusions}

In this work, tooth surface of curve-face gear was determined as the envelope to the family of standard shaper surface, rather than the simulation processing by non-circular shaper. And then, the tooth surface geometry and kinematics of curve-face gear compound transmission were studied. The main conclusions are summarized as follows:

- Moving-axis or fixed-axis input gear mechanism were used for the gear processing or transmission, respectively. Furthermore, the deceleration mechanism with the output of spatial finite helical motion can be acquired when cylindrical gear is as the 
input gear during curve-face gear compound transmission, otherwise acceleration mechanism with the output of complex plane curve motion was obtained.

- The curve-face gear compound transmission satisfies the first law of gearing. And the tooth surface normal is reciprocal to the instantaneous screw. As a result, the curve-face gear compound transmission can realize the conjugate action with desired instantaneous transmission ratio.

- There is no contact point with a pure roll during curve-face gear compound motion, namely, rolling and sliding action coexist at all contact position on the tooth surfaces. Due to the point contact between cylindrical gear and the face-gear in meshing, errors of assembly and manufacturing can be reduced theoretically.

- Tooth surface geometry of curve-face gear can be acquired accurately through the model generated by mathematical method in our current work. Further, the machining accuracy grade of the curve-face gear tooth surface is 9th. Hence, a more precise evaluation on mechanical processing accuracy of tooth surface was also obtained. Significantly, the method mentioned above provides a theoretical basis for following research on machining curve-face gear by standard shaper, which can simplify the design and fabrication of the curve-face gear.

Author Contributions: Conceptualization, Y.H. and C.L.; Methodology, Y.H. and S.L.; Software, Y.Y.; Validation, S.L. and C.H.; Formal analysis, Y.H. and S.L.; Investigation, Z.C.; Resources, C.L.; Data curation, Z.C.; Writing—original draft preparation, Y.H.; Writing—review and editing, S.L.; Visualization, C.H.; Supervision, C.L.; Project administration, C.L.; Funding acquisition, C.L. All authors have read and agreed to the published version of the manuscript.

Funding: This research was funded by National Natural Science Foundation of China, grant number 51675060; Equipment Pre-Research Project, grant number 3010519404; Chongqing Graduate Student Research Innovation Project, grant number CYB19011.

Institutional Review Board Statement: Not applicable.

Informed Consent Statement: Not applicable.

Conflicts of Interest: The authors declare no conflict of interest.

\section{Nomenclature}

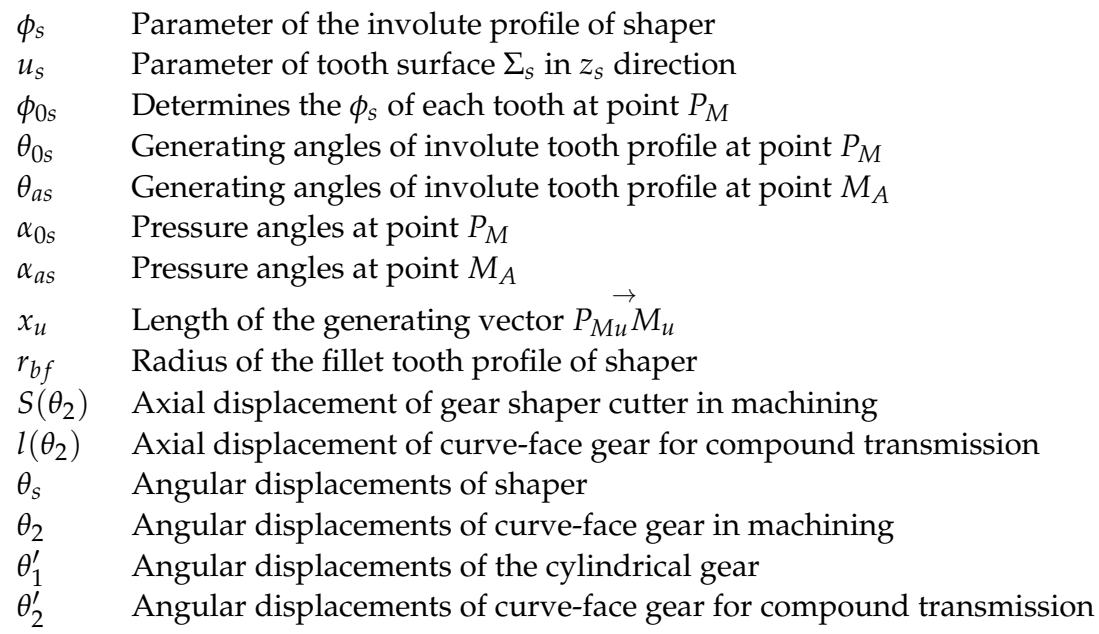

\section{References}

1. Li, Y.; Ge, W.; Zhang, X.; Tong, X. Optimization and Experiment of a Novel Compliant Focusing Mechanism for Space Remote Sensor. Sensors 2020, 20, 6826. [CrossRef] [PubMed]

2. Kraliz, R. Multi-Screw Focusing Mechanism for DMC3 SUB-1m Imager. In Proceedings of the 15th European Space Mechanisms and Tribology Symposium, Noordwijk, The Netherlands, 24-26 September 2013.

3. Hongyu, Q. Research on mechanism reliability of space remote-sensing camera, Chineae Academy of Science (Changchun Institute of Optics, Fine Mechanics and Physics. Ph.D. Thesis, Chinese Academy of Sciences, Beijing, China, 2017. 
4. Lin, C.; He, C.; Hu, Y. Analysis on the kinematical characteristics of compound motion curve-face gear pair. Mech. Mach. Theory 2018, 128, 298-313. [CrossRef]

5. Cai, Z.; Lin, C.; Zhiqin, C.; Chao, L. Research on the Discrete Algorithm of Tooth Surface for a Curve-Face Gear. J. Mech. Des. 2020, 142, 053301. [CrossRef]

6. Litvin, F.L.; Fuentes, A.; Curti, G. Gear Geometry and Applied Theory; Cambridge University Press: Cambridge, UK, 2004; ISBN 9780521815178 .

7. Radzevich, S.P. Theory of Gearing: Kinematics, Geometry, and Synthesis; CRC Press: Boca Raton, FL, USA, 2012.

8. Wu, D.; Luo, J. A Geometric Theory Of Conjugate Tooth Surfaces; World Scientific Publishing Co. Pte. Ltd.: Singapore, 1992; ISBN 9789814360098.

9. Dai, J. Algebra and Kinematic Approaches for Mechanisms and Robotics; Springer: Berlin/Heidelberg, Germany, 2014.

10. Philips, J.R.; Hunt, K.H. On the theorem of three axes in the spatial motion of three bodies. Aust. J. Appl. Sci. 1964, 15, 267-287.

11. Hunt, K.H. Kinematic Geometry of Mechanisms; The Oxford.; The Clarendon Press, Oxford University Press: New York, NY, USA, 1978; ISBN 0-19-856124-5.

12. Dooner, D.B. On the three laws of gearing. J. Mech. Des. Trans. ASME 2002, 124, 733-744. [CrossRef]

13. Dooner, D.B. Kinematic Geometry of Gearing; John Wiley \& Sons, Ltd.: Chichester, UK, 2012; ISBN 9781119942474.

14. Phillips, J. General Spatial Involute Gearing; Springer: Heidelberg/Berlin, Germany, 2003; ISBN 978-3-642-07918-4.

15. Lin, C.; He, C. Analysis of tooth contact and transmission errors of curve-face gear. Proc. Inst. Mech. Eng. Part C J. Mech. Eng. Sci. 2016, 231, 3579-3589. [CrossRef]

16. Lin, C.; Wu, X. Calculation and analysis of contact ratio of helical curve-face gear pair. J. Braz. Soc. Mech. Sci. Eng. 2017, 39, 2269-2278. [CrossRef]

17. Lin, C.; Wei, W.; Wang, S.; Xia, X.; Xin, Q. Bending stress analysis of eccentric straight and helical curve-face gear pair. Int. J. Mech Mater. Des. 2019, 16, 401-414. [CrossRef]

18. Lin, C.; He, C.; Gu, S.-J.; Wu, X.-Y. Loaded tooth contact analysis of curve-face gear pair. Adv. Mech. Eng. 2017, 9. [CrossRef]

19. He, C.; Lin, C. Analysis of loaded characteristics of helical curve face gear. Mech. Mach. Theory 2017, 115, 267-282. [CrossRef]

20. Cai, Z.; Lin, C. Dynamic Model and Analysis of Nonlinear Vibration Characteristic of a Curve-Face Gear Drive. Stroj. Vestn.-J. Mech. Eng. 2017, 63, 161-170. [CrossRef]

21. Lin, C.; Hu, Y.; Yu, Y. Research on the motion characteristics of composite Curve-face gear transmission. J. Adv. Mech. Des. Syst. Manuf. 2019, 13, JAMDSM0036. [CrossRef]

22. Lin, C.; Liu, W.; Xing, Q.; Xia, X.; Tang, P. Calculation and analysis of meshing efficiency of composite motion of the curve-face gear pair. Trans. Can. Soc. Mech. Eng. 2019, 43, 431-441. [CrossRef]

23. Liang, D.; Chen, B.; Gao, Y. Hobbing Manufacturing of New Type of Involute-Helix Gears for Wind Turbine Gearbox. Int. J. Precis. Eng. Manuf. Technol. 2019, 6, 305-313. [CrossRef]

24. Litvin, F.L.; Zhang, Y.; Wang, J.-C.; Bossler, R.B.; Chen, Y.-J.D. Design and Geometry of Face-Gear Drives. J. Mech. Des. 1992, 114, 642-647. [CrossRef]

25. Yang, D.C.H.; Tong, S.-H.; Lin, J. Deviation-Function Based Pitch Curve Modification for Conjugate Pair Design. J. Mech. Des. 1999, 121, 579-586. [CrossRef]

26. Liang, N.; Chen, B.; Gao, Y.; Peng, S.; Qin, S. Geometric and Meshing Properties of Conjugate Curves for Gear Transmission. Math. Probl. Eng. 2014, 2014, 484802. [CrossRef]

27. Zheng, F.; Hua, L.; Han, X. The mathematical model and mechanical properties of variable center distance gears based on screw theory. Mech. Mach. Theory 2016, 101, 116-139. [CrossRef]

28. Fuchs, D. Evolutes and Involutes of Spatial Curves. Am. Math. Mon. 2013, 120, 217-231. [CrossRef]

29. Dooner, D.B.; Griffis, M.W. On Spatial Euler-Savary Equations for Envelopes. J. Mech. Des. 2007, 129, 865-875. [CrossRef]

30. Tseng, R.-T.; Tsay, C.-B. Contact characteristics of cylindrical gears with curvilinear shaped teeth. Mech. Mach. Theory 2004, 39, 905-919. [CrossRef]

31. Wu, Y.-C.; Chen, K.-Y.; Tsay, C.-B.; Ariga, Y. Contact Characteristics of Circular-Arc Curvilinear Tooth Gear Drives. J. Mech. Des. 2009, 131, 081003. [CrossRef]

32. Bair, B.-W.; Sung, M.-H.; Wang, J.-S.; Chen, C.-F. Tooth profile generation and analysis of oval gears with circular-arc teeth. Mech. Mach. Theory 2009, 44, 1306-1317. [CrossRef]

33. Argyris, J.; Fuentes, A.; Litvin, F.L. Computerized integrated approach for design and stress analysis of spiral bevel gears. Comput. Methods Appl. Mech. Eng. 2002, 191, 1057-1095. [CrossRef]

34. Fan, Q. Computerized modeling and simulation of spiral bevel and hypoid gears manufactured by Gleason face hobbing process. J. Mech. Des. Trans. ASME 2006, 128, 1315-1327. [CrossRef]

35. Chen, C.-F.; Tsay, C.-B. Tooth profile design for the manufacture of helical gear sets with small numbers of teeth. Int. J. Mach. Tools Manuf. 2005, 45, 1531-1541. [CrossRef]

36. Gołębski, R.; Boral, P. Study of Machining of Gears with Regular and Modified Outline Using CNC Machine Tools. Materials 2021, 14, 2913. [CrossRef] [PubMed]

37. Boral, P.; Gołębski, R.; Stoić, A. Analysis of Outline Measurements Methods of Spur Gear Involute Profile. Teh. Vjesn.-Tech. Gaz. 2021, 28, 1008-1011. [CrossRef]

38. Gołębski, R.; Ivandić, Z. Analysis of Modification of Spur Gear Profile. Teh. Vjesn.-Tech. Gaz. 2018, 25, 643-648. [CrossRef] 
39. Heath, G.F.; Filler, R.R.; Tan, J. Development of Face Gear Technology for Industrial and Aerospace Power Transmission; NASA/CR-2002211320; NASA: Washington, DC, USA, 2002.

40. Wang, Y.; Su, G.; Chu, X.; Huang, Y.E.S.; Zhang, W.; Liu, Y. A finishing method for the continuous generation of spur face gears with shaving cutters. Int. J. Mech. Sci. 2021, 190, 106020. [CrossRef]

41. Lin, C.; Gong, H.; Nie, N.; Zen, Q.; Zhang, L. Geometry design, three-dimensional modeling and kinematic analysis of orthogonal fluctuating gear ratio face gear drive. Proc. Inst. Mech. Eng. Part C J. Mech. Eng. Sci. 2013, 227, 779-793. [CrossRef]

42. Cai, Z.; Lin, C. Geometric design using undercutting and pointing conditions for a curve-face gear. Adv. Mech. Eng. 2016, 8, 1687814016656964. [CrossRef]

43. Lin, C.; Fan, Y.; Wang, Y.; Cao, X.; Cai, Z. A five-axis CNC machining method of orthogonal variable transmission ratio face gear. J. Adv. Mech. Des. Syst. Manuf. 2014, 8, JAMDSM0040. [CrossRef]

44. Lin, C.; Cai, Z.; Wang, Y. Research on the geometric modeling and tooth-flank characteristic of curve-face gear. J. Adv. Mech. Des. Syst. Manuf. 2016, 10, JAMDSM0033. [CrossRef]

45. Lin, C.; Zeng, D.; Zhao, X.; Cao, X. Numerical Calculation of Tooth Profile of a Non-circular Curved Face Gear. Stroj. Vestn. J. Mech. Eng. 2015, 61, 303-310. [CrossRef]

46. Lin, C.; Huang, C.; Cao, X.-J.; Fan, Y. Geometric error detection of curve-face gear pairs. Adv. Mech. Eng. 2016, 8, 1687814016679311. [CrossRef] 